\title{
Nuclear Safeguards Considerations for the Pebble Bed Modular Reactor (PBMR)
}

Philip Casey Durst

David Beddingfield

Brian Boyer

Robert Bean

Michael Collins

Michael Ehinger

David Hanks

David L. Moses

Lee Refalo

October 2009

The INL is a U.S. Department of Energy National Laboratory

operated by Battelle Energy Alliance

Idaho National 


\title{
Nuclear Safeguards Considerations for the Pebble Bed Modular Reactor (PBMR)
}

\author{
Philip Casey Durst \\ David Beddingfield ${ }^{1}$ \\ Brian Boyer ${ }^{1}$ \\ Robert Bean \\ Michael Collins ${ }^{1}$ \\ Michael Ehinger ${ }^{2}$ \\ David Hanks ${ }^{3}$ \\ David L. Moses ${ }^{2}$ \\ Lee Refalo ${ }^{3}$ \\ ${ }^{1}$ LANL \\ ${ }^{2}$ ORNL \\ ${ }^{3}$ SRNL
}

October 2009

\section{Idaho National Laboratory Idaho Falls, Idaho 83415}

http://www.inl.gov

Prepared for the U.S. Department of Energy

Office of National Nuclear Security Administration

Under DOE Idaho Operations Office

Contract DE-AC07-05ID14517 


\section{Disclaimer}

This information was prepared as an account of work sponsored by an agency of the U.S. Government. Neither the U.S. Government nor any agency thereof, nor any of their employees, makes any warranty, expressed or implied, or assumes any legal liability or responsibility for the accuracy, completeness, or usefulness, of any information, apparatus, product, or process disclosed, or represents that its use would not infringe privately owned rights. References herein to any specific commercial product, process, or service by trade name, trade mark, manufacturer, or otherwise, does not necessarily constitute or imply its endorsement, recommendation, or favoring by the U.S. Government or any agency thereof. The views and opinions of authors expressed herein do not necessarily state or reflect those of the U.S. Government or any agency thereof. 


\section{EXECUTIVE SUMMARY}

High temperature reactors (HTRs) have been considered since the 1940s and have been constructed and demonstrated in the United Kingdom (Dragon), United States (Peach Bottom and Fort Saint Vrain), Japan (HTTR), Germany (AVR and THTR-300), and have been the subject of conceptual studies in Russia (VGM). The attraction to these reactors is that they can use a variety of reactor fuels, including abundant thorium, which upon reprocessing of the spent fuel can produce fissile U-233. Hence, they could extend the stocks of available uranium provided the fuel is reprocessed. Another attraction is that HTRs typically operate at a much higher temperature than conventional light water reactors (LWRs), because of the use of high melting-point pyrolytic carbon and silicon carbide coated (TRISO) fuel particles embedded in ceramic graphite. Rather than simply discharge most of the unused heat from the working fluid in the power plant to the environment, engineers have been designing HTRs for 40 years to recover heat and make it available for district heating or chemical conversion plants. Demonstrating hightemperature nuclear energy conversion was the purpose behind Fort Saint Vrain in the United States, THTR-300 in Germany, HTTR in Japan, and HTR-10 and HTR-PM being built in China. This resulted in nuclear reactors at least $30 \%$ or more thermodynamically efficient than conventional LWRs, especially if the waste heat can be effectively utilized in chemical processing plants.

A modern variant of high temperature reactors is the Pebble Bed Modular Reactor (PBMR). Originally developed in the United States and Germany, it is now being redesigned and marketed by the Republic of South Africa and China. What is interesting about this reactor is that the fuel is not integral hexagonal (prismatic) blocks of graphite with embedded uranium carbide fuel particles, but instead consists of small $6 \mathrm{~cm}$ diameter spheres or pebbles, roughly the size and shape of tennis balls. In the current scheme, the fuel is fed into the reactor from a fresh fuel storage bin, recirculated up to six times to achieve optimum burn-up, and then flows out of the reactor into spent fuel storage bins. The International Atomic Energy Agency (IAEA) that safeguards nuclear reactors worldwide considers the conventional LWR an "item facility," because the fuel is discrete and integral and can be randomly identified and verified as an item. The new PBMR and related reactors are more like a "bulk material facility," in which the fuel is in bulk form - as stored in fresh fuel drums, the core, and spent fuel storage bins.

Since the PBMR design is expected to be less expensive and easier to market to developing countries than LWRs, the U.S. DOE/NNSA Office of NA-243 commissioned a group of American international nuclear safeguards experts and technologists to consider the unique nuclear safeguards implications that would be posed by the spread of the PBMR design. The manufacturer of the reactor, PBMR (Pty.) Ltd., hopes to begin construction of the flagship reactor in 2014 operation in 2018. Thereafter, the firm hopes to start-up follow-on reactors every two years, depending on customer demands. Specific orders for the PBMR have not yet been made public, although it is assumed that the South African national electric utility, Eskom, will be a major customer. Countries that have inquired of PBMR (Pty.) Ltd. regarding the nuclear reactor include: Turkey, Chile, Argentina, Peru, Brazil, Indonesia, Malaysia, Vietnam, Nigeria, Ghana, Tunisia, and Algeria. Kenya, Uganda, Egypt, Morocco, and Namibia also have publicly declared intentions to develop nuclear power and could be potential customers for the PBMR as well. Current investors in the PBMR include the South African Government, Eskom, Industrial Development Corporation of South Africa Ltd. (IDC), Westinghouse Electric Company (WEC), and Exelon. The investors have spent an estimated 7 billion Rand (US\$ 860 million) to demonstrate the PBMR since 1999, with the South African Government being the major investor.

The DOE National Laboratory PBMR Safeguards Team examined the PBMR and reviewed safeguards considerations for this basic reactor type. The following is a preliminary report on this topic prepared under the ASA-100 Advanced Safeguards Project in support of the NNSA Next Generation Safeguards Initiative (NGSI). It is considered a preliminary report because the South African PBMR is being down-sized and redesigned for enhanced energy recovery and to make it more affordable to potential customers. Consequently, the design may not be finalized for one to two more years. 
Nonetheless, the fundamental safeguards issues are inherent to the bulk nature of the fuel and on-load refueling of the PBMR, which are still worthy of discussion, even in a preliminary report.

Based on the fundamental aspects and current design of the PBMR, the National Laboratory PBMR Safeguards Team drew the following conclusions:

1. The IAEA Safeguards Criteria does not fit the Pebble Bed Modular Reactor, under the categories of light water reactor (LWR), on-load refueled reactor (OLR, i.e. CANDU), or "Other." Because the nuclear fuel is dispersed across such a large bulk of material, it could be classified as a "bulk-fuel reactor," and unique safeguards criteria should be developed for this reactor type by the IAEA, in cooperation with affected IAEA Member States, and international safeguards partners, such as U.S. DOE and NNSA.

2. In developing the new safeguards criteria, the IAEA should consider the bulk nature of the fuel. The traditional requirement to identify discrete fuel assemblies in the LWR, OLR or Other-type reactors, and verify those randomly for uranium, U-235, plutonium, and/or thorium content, does not seem feasible or relevant in the case of the PBMR. Verification of the fresh, core and spent fuel are more akin to U-235 or plutonium verification in a uranium or MOX fuel fabrication plant. DOE/NNSA should work with the IAEA to make certain that this aspect is practically addressed, and that undue emphasis is not placed on the identification and verification of individual fuel pebbles.

3. The ideal safeguards approach appears to be a hybridized approach employing fuel flow monitoring, redundant advanced containment and surveillance, and bulk nuclear material accountancy and verification techniques. This layered approach would provide a safeguards "defense in depth" that the item facility and bulk facility approach cannot provide alone.

4. The IAEA originally considered whether nuclear material in spent PBMR fuel was irrecoverable because of the highly refractory nature of the fuel. However, reprocessing of similar HTGR fuel has been demonstrated in the United States at the Idaho Chemical Processing Plant (ICPP). Consequently, the recovery of plutonium and uranium from PBMR spent fuel must be considered possible, although technically challenging. This has been confirmed by a separate Idaho National Laboratory (INL) report on the subject.

5. Close cooperation between PBMR (Pty) Ltd., the IAEA, DOE/NNSA, and the DOE National Laboratories to develop a safeguards approach, is essential to address the unique nature of the PBMR (i.e., continuous on-load refueling with nuclear fuel in bulk form).

Based on the conclusions noted, the National Laboratory PBMR Safeguards Team recommends the following next steps to NNSA, in relative order of priority:

Near-term (6 Months to 1 Year)

1. Recommend to the IAEA Department of Safeguards, Operations Division SGOB and the Division of Concepts and Planning (SGCP), the development of new safeguards criteria better suited to safeguarding the PBMR and other bulk-fuel reactors. This recommendation has previously been supported by the IAEA when the development of the PBMR was first made public.

2. Support the National Laboratory PBMR Safeguards Team to re-evaluate the safeguards considerations and optimum safeguards approach for the reactor, once the redesign of the reactor has been finalized.

3. Request a detailed briefing from the reactor developer, PBMR (Pty.) Ltd., to review the recent design changes so that NNSA can help support PBMR safeguards by focusing research and development in support of safeguards tools and equipment amenable to improving the safeguarding of this and related bulk-fuel reactors likely to be marketed. 
4. Raise the PBMR safeguards issues and concerns noted to PBMR (Pty.) Ltd. so reactor designers can make provisions for the proposed safeguards systems including: the IAEA Next Generation Surveillance System (NGSS), EOSS next generation sealing system, and custom designed fuel flow monitors. The facility design should also accommodate the tracing and verification of the extensive fuel transfer system during the IAEA design information examination and verification activity (DIE/DIV). The designer should consider how the extensive fuel transfer paths would be re-verified by the IAEA, once the facility goes hot and operational. The redesign of the reactor allows a window for more detailed and timely nuclear safeguards input in keeping with the concept of Safeguards-byDesign.

Mid-term (1 to 3 Years)

1. Continue to support development and optimization of: i) techniques to verify the plutonium content or radiation attributes of spent fuel pebbles, ii) burn-up computer codes for PBMR spent fuel, and iii) bulk verification techniques for PBMR spent fuel storage bins. The need to reverify the spent fuel storage bins at some point in the future is likely, and the IAEA will need the tools to perform this task - which they do not presently have. More accurate non-destructive assay techniques for verifying the recirculating PBMR core and spent fuel could ultimately lead to a continuous on-line assay system that could be used jointly by the inspector for safeguards purposes and plant operator for monitoring fuel burn-up and reactor performance. The first two issues are currently being supported by NA 24, but the third item has not previously been defined as a need.

2. Continue to support development of the IAEA Next Generation Surveillance System (NGSS), which would greatly aid the implementation of safeguards at the PBMR and other nuclear facilities under IAEA safeguards.

3. Continue to support the development and vulnerability testing of the next generation IAEA Electro-Optical Sealing System (EOSS), which would greatly aid the implementation of safeguards at the PBMR and other nuclear facilities under IAEA safeguards.

4. Support the development of effective fuel flow monitors for the PBMR. The optimized design of the flow monitors will depend on the results of the PBMR spent fuel characterization and modeling studies currently in progress. For the PBMR safeguards approach to be effective, the flow monitors need to be able to reliably discriminate between irradiated graphite moderator spheres, fresh fuel, low burn-up fuel, and high burn-up spent fuel. This has yet to be practically demonstrated.

Long-term (3 to 5 years)

1. Recommend that the IAEA begin field design information examination and verification (DIE/DIV) of the reactor as soon as construction begins, tentatively scheduled for 2014.

2. During the DIE/DIV, recommend that the IAEA pay particular attention to the verification and testing of the numerous fuel flow monitors and the need for bulk volume measurement systems, especially for the spent fuel bins, used fuel bin, graphite ball storage bin, damaged fuel bins, etc.

3. Support the IAEA in developing an effective safeguards approach for the PBMR, which needs to be implemented prior to the 2018 start-up of the demonstration reactor in Koeberg, South Africa. 


\section{ACKNOWLEDGEMENTS}

Funding for performing this study and preparing the report was provided by the U.S. DOE/NNSA Office of International Regimes and Agreements (NA-243) under the Advanced Safeguard Approaches

Project (ASA-100) in support of the Next Generation Safeguards Initiative (NGSI). The authors wish to thank the sponsors in NA-243 for their support, guidance and input. The authors also wish to thank Ms. Miriam Ogden for administrative support and Mr. Gordon Holt and Quinn Grover at the Idaho National Laboratory for editing the final report. 


\section{CONTENTS}

EXECUTIVE SUMMARY vi

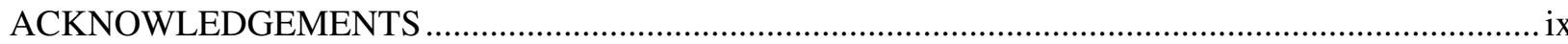

LIST OF ACRONYMS AND ABBREVIATIONS............................................................................

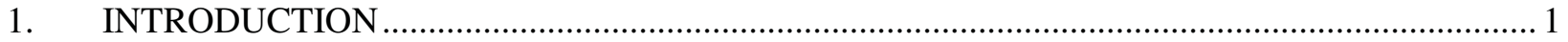

1.1 History and Evolution of High Temperature Gas Reactors (HTGR) ..................................... 1

1.2 Pebble Bed Modular Reactor - A Reactor for the Future? ................................................ 4

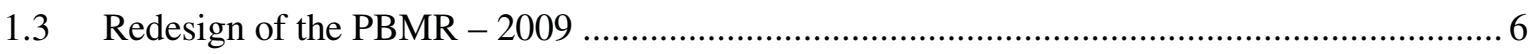

1.4 The New Reactor Needs a New Safeguards Approach....................................................... 7

2. INTERNATIONAL NUCLEAR SAFEGUARDS REQUIREMENTS ….................................. 9

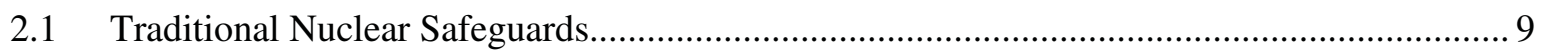

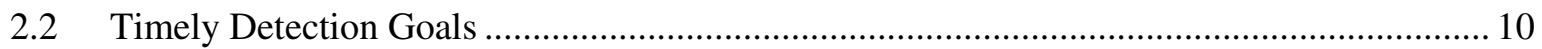

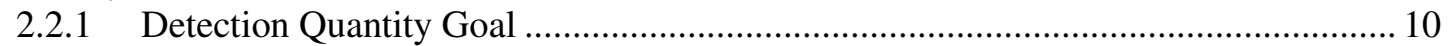

2.2.2 Deterrence by Risk of Early Detection - Probability of Detection Goals .................. 10

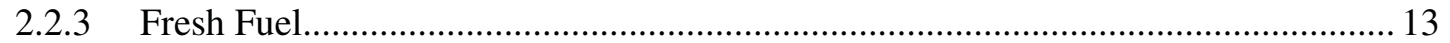

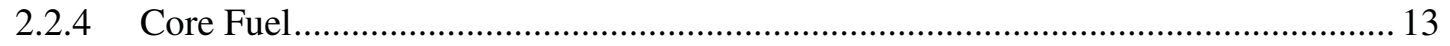

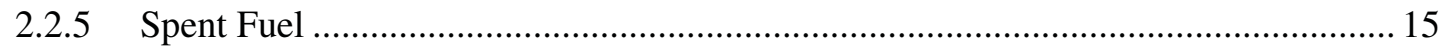

2.3 Summary of PBMR Fundamental Safeguards Issues ................................................... 15

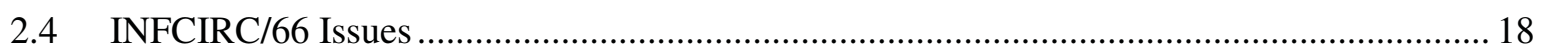

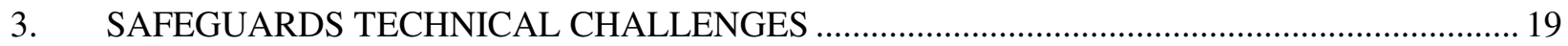

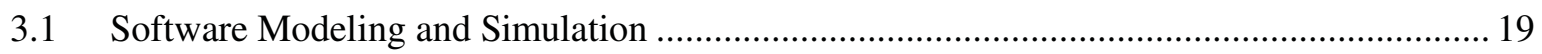

3.2 Composition of PBMR Core and Spent Fuel .................................................................. 19

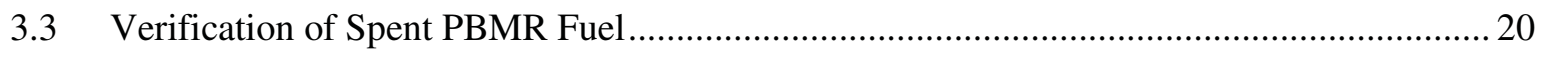

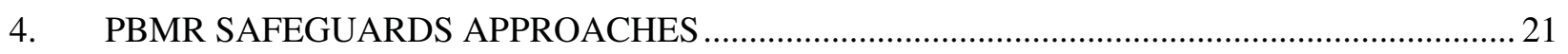

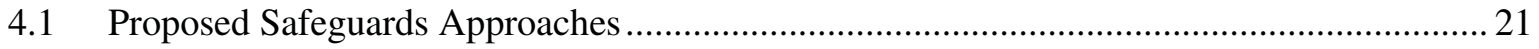

4.2 Review of the Number-Balance (Flow Monitor) Approach …......................................... 22

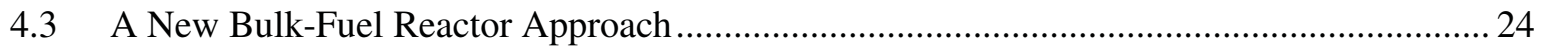

4.4 Challenge of Facility Design Information Verification (DIV) for PBMR …....................... 26

4.5 Safeguards-by-Design Considerations ............................................................................. 29

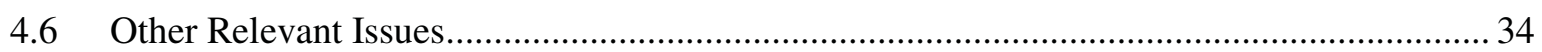

4.6.1 Spent PBMR Fuel - Can it be Reprocessed? ........................................................ 34

4.6.2 Is Plutonium in Spent PBMR Fuel Weapons Usable? ........................................... 35

4.6.3 Anti-Neutrino Detectors as a Safeguards Tool for the Future .................................. 36

4.6.4 Aspects of the Long-term Storage of Spent PBMR Fuel ....................................... 37

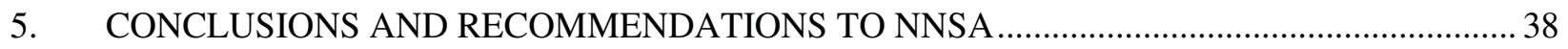

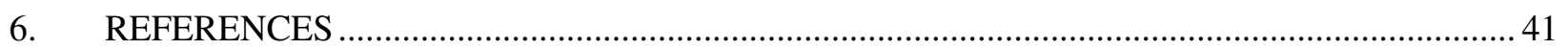




\section{FIGURES}

Figure 1: Cross-sectional View of 165 MWe PBMR Reactor Building (Source - PBMR Ltd., ca. 2008)

Figure 2: Redesign of the PBMR - From 400 MWth to 200 MWth with Cogeneration (Source Westinghouse Electric Co., June, 2009).

Figure 3: Proposed Nuclear Material Balance Area (MBA) and Key Measurement Points (KMP) for the PBMR (NL=Nuclear Decay (Loss), NP = Nuclear Production, PIE = Post Irradiation Examination) (Source - Los Alamos National Laboratory).....

Figure 4: Schematic of the Proposed Safeguards Approach for the PBMR Showing Safeguards Measures (Source - J. Slabber, PBMR (Pty.) Ltd.).

Figure 5: Cross-sectional View of PBMR Reactor Building Showing Relative Location of Fresh Fuel and Spent Fuel Storage Areas (Source - PBMR Ltd.).

\section{TABLES}

Table 1: Worldwide PBMR and Related Reactors (Source - Los Alamos National Laboratory)................. 3

Table 2: IAEA Timeliness Goals for Detecting Diversions of PBMR Nuclear Materials (Source IAEA Safeguards Glossary - 2001)

Table 3: Relevant IAEA Detection Quantity Goals or a PBMR (Source - IAEA Safeguards Glossary, 2001) 10

Table 4: IAEA Specified Probabilities for Detecting Diversions of Nuclear Material Relevant to a PBMR (Source - IAEA Safeguards Criteria, Other Reactors, 2003).

Table 5: PBMR Fuel Pebble Composition \& Number of Pebbles per Significant Quantity (SQ) (Source - Todd et al., INL, 2006)

Table 6: Proposed Verification Measures by KMP with Diversion Threats. 16

(Color coded to MBA Diagram, Figure 3) (Source - Idaho and Los Alamos National Laboratory, 2009) 16

Table 7: Nuclear Facility Life Cycle and IAEA DIE/DIV Related Activities (Source - IAEA Safeguards Manual, SMI-4.1, 2003) 


\section{LIST OF ACRONYMS AND ABBREVIATIONS}

3DLR 3-Dimensional Laser Range Finder (also called LIDAR, 3DLRF and 3DLRFD)

AEC U.S. Atomic Energy Commission (ca. 1945 to 1977)

AFR Away-from-Reactor Storage (of Spent Fuel)

AP (IAEA) Additional Protocol

ATR Advanced Test Reactor (at INL)

AVR Arbeitsgemeinschaft Versuchsreactor (Developmental Test Reactor) (Germany)

AWCC Active Well Coincident-Neutron Counter

BISO Bi-layer Coating for Fuel Particles used in High Temperature Reactors

CANDU Canadian Deuterium/Uranium Reactor

CCI Compact Compton Imager

CF Core Fuel

CINDER An Early Spent Fuel Burnup Code

$\mathrm{C} / \mathrm{S} \quad$ Containment /Surveillance

$\mathrm{Cm} \quad$ Curium, Chemical Symbol

CofK Continuity of Knowledge, also called C-o-K

COTS Commercial Off-the-Shelf

CUD Core Unloading Device (South African PBMR)

d Day

DA Destructive (Chemical) Analysis

DI Design Information

DIE Design Information Examination

DIV Design Information Verification

DIVP Design Information Verification Plan

DOE U.S. Department of Energy

DT Deuterium/Tritium (Neutron Generator)

DU Depleted Uranium (Uranium with less than $0.71 \%$ U-235)

EEL (IAEA) Essential Equipment List

EFL U.S. Eligible Facility List 


\begin{tabular}{|c|c|}
\hline EOSS & (IAEA) Next Generation Electro-Optical Sealing System \\
\hline ES & Environmental (Swipe) Samples \\
\hline Eskom & The South African National Electric Utility (Potential Customer for the PBMR) \\
\hline FBR & Fast Breeder Reactor \\
\hline FF & Fresh Fuel \\
\hline FHSS & Fuel Handling and Storage System (South African PBMR) \\
\hline FSV & Fort St. Vrain Reactor (United States) \\
\hline GAC & General Atomics Corporation (United States) (Also called GA) \\
\hline GCTR & Gas Cooled Test Reactor \\
\hline GEN IV & International Generation-IV Advanced Reactor Project \\
\hline GFR & Gas Cooled Fast Reactor \\
\hline GPS & Global Positioning System \\
\hline GTMHR & Gas Turbine Modular Helium Reactor (U.S. and Russia) \\
\hline GTHTR & Gas Turbine High Temperature Reactor (Japan) \\
\hline GWD/t & Gigawatt-Days per Tonne (Spent Fuel Burnup) \\
\hline HEU & Highly Enriched Uranium \\
\hline HM-5 & (IAEA) Handheld Radiation Meter Model-5 \\
\hline HTGR & High Temperature Gas Reactor \\
\hline HTR & High Temperature Reactor \\
\hline HTR-10 & High Temperature Reactor, 10 MWth (China) \\
\hline HTR-PM & High Temperature Reactor, Production Model (China) \\
\hline IAEA & International Atomic Energy Agency \\
\hline ICPP & Idaho Chemical Processing Plant \\
\hline ID & Identification \\
\hline IDC & Industrial Development Corporation of South Africa Ltd. \\
\hline IIV & (IAEA) Interim Inventory Verification \\
\hline INET & Institute of Nuclear and New Energy Technology (Tsinghua, China) \\
\hline INFCIRC/66 & (IAEA) Early Safeguards Agreement (now limited to India, Israel and Pakistan) \\
\hline INFCIRC/153 & (IAEA) Model Comprehensive Safeguards Agreement \\
\hline INFCIRC/540 & (IAEA) Model Additional Protocol (AP) \\
\hline
\end{tabular}


INL (U.S. DOE) Idaho National Laboratory (also formerly INEL and INEEL)

KMP (IAEA) Nuclear Material Key Measurement Point

JAEA Japan Atomic Energy Agency (formerly JNC and PNC)

JRC Joint Research Centre of the European Commission

KFA (Federal Republic of Germany) Nuclear Research Center

KFA-Jülich German Nuclear Research Center in Jülich, Germany

LANL (U.S. DOE) Los Alamos National Laboratory

LBNL (U.S. DOE) Lawrence Berkley National Laboratory

LEU Low Enriched Uranium

LIDAR Light Detection and Ranging

LLNL (U.S. DOE) Lawrence Livermore National Laboratory

LWR Light Water Reactor

MBA (IAEA) Material Balance Area

MCNPX Monte Carlo Neutron Production Software Code-X

MMCA (IAEA) Mini Multi-Channel (Gamma Spectrum) Analyzer

MMCN (IAEA) Mini Multi-Channel Analyzer with Sodium (Na) Detector

MMCG (IAEA) Mini Multi-Channel Analyzer with Germanium Detector

MOX Mixed Plutonium/Uranium Oxide

MT Metric Tonnes, also just Tonnes

MUF Material Unaccounted For

MWd Megawatt-Days (Reactor Power Output)

MWd/t Megawatt-Days per Tonne (Spent Fuel Burnup)

MWe Megawatts, Electric

MWth Megawatts, Thermal

NA 24 NNSA Office of International (Safeguards) Regimes and Agreements

NDA Non-Destructive Analysis

NEA Nuclear Energy Agency (OECD)

NGNP Next Generation Nuclear Plant

NGSI (DOE/NNSA) Next Generation Safeguards Initiative

NGSS (IAEA) Next Generation Surveillance System 
NMIS Nuclear Material Identification System

NNSA National Nuclear Security Administration

NNWS (NPT) Non-Nuclear Weapons State

NPT Treaty on the Non-Proliferation of Nuclear Weapons

NRC U.S. Nuclear Regulatory Commission

NU Natural Uranium

NWS (NPT) Nuclear Weapons State

OECD Organization for Economic Cooperation and Development

OLR On-Load Refueled Reactor

ORIGEN Oak Ridge Spent Fuel Burnup Code

OVS Outdoor Viewing System

$\mathrm{Pb} \quad$ Lead, Chemical Symbol

PBMR Pebble Bed Modular Reactor (Germany and Republic of South Africa)

PBMR (Pty)Ltd. Company in South Africa Designing and Marketing the PBMR

PIE Post-Irradiation Examination

PIV Physical Inventory Verification

PNNL (U.S. DOE) Pacific Northwest National Laboratory

PP Physical Protection

PRC People's Republic of China (China)

$\mathrm{Pu} \quad$ Plutonium, Chemical Symbol

Pu-239 The Prominent Fissile Isotope of Plutonium (Over 90\% is considered Weapons Grade)

Pu-240 A Higher Isotope of Plutonium that Degrades Weapons Usability above 20\%

PUREX Plutonium and Uranium Reduction and Extraction

PWR Pressurized Water Reactor

RBMK Soviet Era On-Load Refueled Reactor (Graphite Moderated) (Russia, Former USSR)

ROVER Rocket Propulsion Very High Temperature Experimental Reactor (United States)

RPV Reactor Pressure Vessel

RSA Republic of South Africa

Sasol South African Standard Oil

SBD Safeguards by Design 
SIR (IAEA) Annual Safeguards Implementation Report

SNL $\quad$ (U.S. DOE) Sandia National Laboratory

SNRI (IAEA) Short-Notice Random Inspection

SRS (U.S. DOE) Savannah River Site

SQ

(IAEA) Significant Quantity

SSAC State System of Accounting for and Control of Nuclear Material

$\mathrm{t}_{1 / 2} \quad$ Isotope half-life

Th Thorium, Chemical Symbol

THM Tonnes Heavy Metal (Uranium, Plutonium, and Actinides in Spent Fuel)

THOREX Thorium Reduction and Extraction

THTR Thorium High Temperature Reactor (Germany)

TRISO Tri-Layer Coating for Fuel Particles used in High Temperature Reactors

U Uranium, Chemical Symbol

U-233 Fissile Isotope of Uranium, Produced by Irradiating Thorium

U-235 Fissile Isotope of Uranium, Typically $0.71 \%$ of Uranium Found in Nature

U-235\% Uranium Enrichment Level (U-235 fraction as percent of total uranium)

U-238 Non-Fissile Isotope of Uranium, Constituting the Bulk of Natural Uranium (over 99\%)

UK United Kingdom of Great Britain and Northern Ireland (i.e. United Kingdom)

VGM Modular High Temperature Reactor (Former Soviet Union)

VHTR Very High Temperature Reactor

VIC Vienna International Centre

WEC Westinghouse Electric Company

XRF X-Ray Fluorescence 
(This page left intentionally blank) 


\section{Nuclear Safeguards Considerations For The Pebble Bed Modular Reactor (PBMR)}

\section{INTRODUCTION}

\subsection{History and Evolution of High Temperature Gas Reactors (HTGR)}

High temperature reactors (HTRs) have been considered since the 1940s, and have been constructed and demonstrated in the United Kingdom (Dragon), United States (Peach Bottom and Fort Saint Vrain), Japan (HTTR), China (HTR-10), Germany (AVR and THTR-300), and have been the subject of conceptual studies in Russia (VGM). ${ }^{1}$ The attraction to these reactors is that they can use a variety of reactor fuels, including abundant thorium, which, upon reprocessing of the spent fuel, can produce fissile $\mathrm{U}-233 .{ }^{2,3}$ Consequently, they could extend the stocks of available uranium, provided the fuel is reprocessed. Another attractive attribute is that they typically operate at a much higher temperature than conventional light water reactors (LWR), because of the use of high melting-point pyrolytic carbon and silicon coated (TRISO) fuel particles embedded in a graphite matrix. ${ }^{4}$ Rather than simply discharge most of the unused heat from the working fluid in the power plant to the environment, engineers have been designing reactors for 40 years to recover this heat and make it available for district heating or chemical conversion plants. This was the demonstrated purpose behind Fort St. Vrain in the United States, THTR300 in Germany, HTTR in Japan, and HTR-10 and HTR-PM being built in China. Achieving higher energy conversion would result in a reactor that is at least $30 \%$ or more thermodynamically efficient than conventional LWRs, especially if the waste heat could be effectively utilized in chemical processing plants.

The concept of an HTR pebble bed reactor was originally envisioned by a researcher for the U.S. Atomic Energy Commission (AEC) in 1944, who patented the idea in the United States after declassification. ${ }^{5,6}$ Prior to declassification, the AEC had sponsored thermal-hydraulic analyses of the concept at the Atomic Energy Commission's Oak Ridge National Laboratory (ORNL). ${ }^{8}$ The AEC sponsored the development of conceptual designs for both a power reactor and an experimental reactor in the late 1950s, before deciding to solely pursue the Peach Bottom prismatic-HTR, which had more industrial support. ${ }^{9,10,11}$ In the early 1960s, the AEC authorized ORNL to pursue joint development of the pebble bed HTR with German researchers at the Federal Republic of Germany's Nuclear Research Center (KFA) in Jülich. The concept was separately patented in Europe and developed as a commercial product by Brown, Boveri, and Cie Aktiengesellschaft in Germany. ${ }^{12,13}$ From 1962 until the late 1980s, ORNL and KFA-Jülich cooperated under a series of Cooperation Agreements between the United States and the Federal Republic of Germany. These included researching aspects of the HTR fuel cycle, coated particle fuel development, and fuel reprocessing technologies for the highly enriched uranium/thorium (HEU/Th) fuel that was the primary candidate fuel for HTRs until the late 1970s. KFA-Jülich also participated in the British led Dragon Project, under the auspices of the Organization for Economic Cooperation and 
Development (OECD), which refocused development toward using low-enriched uranium (LEU) in place of HEU in the 1970s.

A modern variant of the HTGR is the Pebble Bed Modular Reactor (PBMR), originally developed by the United States and Germany, but now being redesigned and marketed by the Republic of South Africa and China. What is interesting about this reactor is that the fuel is not integral hexagonal (prismatic) blocks of graphite with embedded uranium carbide fuel particles, but instead consists of small $6 \mathrm{~cm}$ spheres or pebbles, roughly the size and shape of tennis balls. In the current scheme, the fuel is fed into the reactor from a fresh fuel storage bin, and recirculated at least six times to allow optimum fuel burnup. It then flows out of the reactor into spent-fuel storage bins. The International Atomic Energy Agency (IAEA), which safeguards nuclear reactors worldwide, considers the conventional LWR an "item facility," because the fuel is discrete and integral can be individually identified and verified. The new PBMR and related reactors are more like a "bulk material facility," in which the fuel is in bulk form - as stored in the fresh fuel bins, the core, and in the spent fuel bins. Since the PBMR design is expected to be less expensive and easier to market to developing countries than LWRs, the NNSA Office of NA-243 commissioned a group of American international nuclear safeguards experts and technologists to consider the unique nuclear safeguards implications that would be posed by the spread of this particular reactor.

The manufacturer of the reactor, PBMR (Pty) Ltd., hopes to begin construction of the flagship reactor in 2014 and its operation in 2018. ${ }^{14}$ Thereafter, the firm hopes to start-up follow-on reactors every two years, depending on customer demand. Specific orders for the PBMR have not yet been made public, although it is assumed that Eskom, the South African national electrical utility, would be a major customer. Countries that have inquired of PBMR (Pty) Ltd. regarding the PBMR include: Turkey, Chile, Argentina, Peru, Brazil, Indonesia, Malaysia, Vietnam, Nigeria, Ghana, Tunisia, and Algeria. Kenya, Uganda, Egypt, Morocco, and Namibia also have publicly declared intentions to develop nuclear power and could be potential customers for the PBMR as well. ${ }^{15}$ Current investors in the PBMR include the South African Government, Eskom, Industrial Development Corporation of South Africa Ltd. (IDC), Westinghouse Electric Company (WEC), and Exelon. The investors have spent an estimated 7 billion Rand (US $\$ 860$ million) to demonstrate the PBMR since 1999, with the South African Government being the largest investor.

In the course of this study, the DOE National Laboratory Team examined the PBMR and reviewed safeguards considerations for this basic reactor type. The following report is a preliminary report that addresses these issues and was prepared under the ASA-100 Advanced Safeguards Project in support of the NNSA Next Generation Safeguards Initiative (NGSI). ${ }^{16}$ It is considered a preliminary report, because the South African PBMR is being redesigned for enhanced energy recovery and to make it more affordable. Consequently, the design may not be finalized for one to two more years. Nonetheless, the National Laboratory Team believes that the fundamental safeguards issues are inherent to the on-load refueling of the reactor with nuclear fuel in bulk form, which are still worthy of discussion, even in a preliminary report.

The intent of this study is to aid the IAEA in the further development and optimization of their model safeguards approach for this new reactor type. At the May, 2009 meeting of the United States Support Program to the IAEA in Vienna, Austria, the IAEA Department of Safeguards indicated that they would wait to see the features of the redesigned PBMR, before they revisit the further development or modification of the IAEA Model Safeguards Approach for the PBMR. ${ }^{17}$ Despite not having a finalized PBMR design, the National Laboratory PBMR Safeguards Team studied this reactor to better understand the unique safeguards issues. The redesign period may also be fortuitous. The National Laboratory PBMR Safeguards Team identified a number of safeguards issues, which could potentially be considered and addressed by PBMR (Pty) Ltd. during this period, such as making provisions for the new safeguards containment and surveillance systems and fuel flow monitors, considered essential to the safeguards approach. It also allows the designer to make provisions to facilitate the IAEA design information 
examination and verification activity (DIE/DIV), especially for the extensive fuel transfer system. More will be said about this in Section-4.5, "Safeguards-by-Design Considerations."

Table 1 lists the PBMR and related reactors that have been planned or constructed since the 1960s. Of these, only the HTR-10 is operational, although roll-out of the South African PBMR has been announced by PBMR Ltd. for 2018.

Table 1: Worldwide PBMR and Related Reactors (Source - Los Alamos National Laboratory)

\begin{tabular}{|c|c|c|c|c|c|c|}
\hline Reactor & VGM & AVR & THTR & PBMR & HTR-10 & HTR-PM \\
\hline Country & $\begin{array}{c}\text { USSR } \\
\text { (Russia) } \\
\end{array}$ & Germany & Germany & South Africa & China & China \\
\hline Operation Start Date & NA & 1967 & 1984 & 2018 & 2004 & TBD \\
\hline Operation Finish Date & NA & 1988 & 1990 & TBD & TBD & TBD \\
\hline Rated Power (MWth) & 250 & 46 & 750 & 400 & 10 & $2 \times 250$ \\
\hline Number of Pebbles in core & & 40,000 & 670,000 & 452,000 & 27,000 & \\
\hline Pebble Diameter (cm) & & & 6 & 6 & 6 & \\
\hline U HM/pebble & 7.0 & 7.0 & $\begin{array}{c}0.96 \mathrm{~g} \mathrm{U}-235 \\
10.2 \mathrm{~g} \mathrm{Th} \\
\end{array}$ & 9.0 & 5.0 & \\
\hline U enrichment (\%235) & $6.5-10.0$ & 10.6 & & $5.7-9.6$ & 17 & 8.9 \\
\hline Pebble Flow Rate (/day) & & & & 500 & 100 & \\
\hline $\begin{array}{c}\text { Number of core passes in } \\
\text { Pebble Lifetime }\end{array}$ & & & & $6-10$ & 0 & \\
\hline Discharge Rate (/day) & & & & 490 & 0 & \\
\hline $\begin{array}{l}\text { Discharge Burnup } \\
\text { (GWd/tonne) }\end{array}$ & $\sim 65$ & $\sim 65$ & & 90.8 & 80 & \\
\hline $\mathrm{Pu} /$ pebble at discharge $(\mathrm{g})$ & & & & 0.114 & 0.08 & \\
\hline
\end{tabular}




\subsection{Pebble Bed Modular Reactor - A Reactor for the Future?}

The Republic of South Africa (South Africa) and the People's Republic of China are both developing and planning to market a modular high temperature nuclear reactor that they believe will be more affordable and more suitable for developing countries. Worldwide nuclear power projections expect this market to become the foundation for future nuclear expansion, especially in South Asia, Africa, and the Near East. Although China also has an interest, in its high temperature reactor production model (HTRPM) and has developed a $10 \mathrm{MWth}$ test version, the HTR-10, this study focuses on the South African PBMR. The study concentrates on the overarching safeguards features of this generic reactor type, which can be best described as a "Bulk-Fuel Reactor."

From the perspective of the suppliers, the main selling features of the PBMR compared to the conventional LWR are: ${ }^{: 18}$

- Smaller, more modular design and construction (ranging from $165 \mathrm{MWe}$ to $80 \mathrm{MWe})^{\mathrm{a}}$

- Amenable to incremental expansion (especially suitable for newly developed areas)

- Shorter construction and financing cycles, because of the modular construction (four to two years)

- Higher thermodynamic energy conversion efficiency (at least 30\% higher than conventional LWRs)

- Competitive and affordable electrical generating cost per MW

- Highly refractory spent nuclear fuel, which is challenging to reprocess for extracting plutonium.

Although historically, neither South Africa, nor China have been significant suppliers of nuclear reactors or technology, this could change in the $21^{\text {st }}$ century. Twenty years ago, China was seen as a populous country, but not the economic super power and trading partner it is today. With this in mind, consideration of an optimized safeguards approach for the PBMR is a relevant topic for international nuclear safeguards discussion - especially if the Chinese are eager to enter the market for selling modular nuclear reactors of this generic design.

\footnotetext{
${ }^{a}$ The original design of the South African PBMR was a $400 \mathrm{MWth}(165 \mathrm{MWe})$ modular nuclear reactor with onload refueling, using spherical fuel pebbles. In the course of this preliminary safeguards study, the makers of the reactor, PBMR Ltd., announced that they would down-size the reactor from $165 \mathrm{MWe}$ to $80 \mathrm{MWe}$.
} 
Regarding the South African PBMR, a reactor ranging in size from 165 MWe to 80 MWe is being considered. ${ }^{19,20}$ The reactor would be a high-temperature, helium gas cooled reactor, modularly prefabricated and erected on site, to permit easier licensing and expansion for increased power production. The fuel will consist of highly refractory $6 \mathrm{~cm}$ diameter spheres, made of a proprietary technology that uses TRISO, $0.5 \mathrm{~mm}$ diameter $\mathrm{UO}_{2}$ fuel kernels. This will permit the reactor to operate well above the normal operating temperatures of LWRs, which also results in its higher energy conversion efficiency, and discharge of waste heat that could be recovered for use in chemical conversion processes. A cross-sectional view of the 400 MWth (165 MWe) PBMR is shown below, with the tall reactor pressure vessel shown in the center. The fresh fuel feed location would be to the right of the facility, as shown above the reactor head, to permit gravity feeding of fuel pebbles to the reactor. The six spent-fuel storage bins would appear to the lower left hand corner in sub-basement levels.

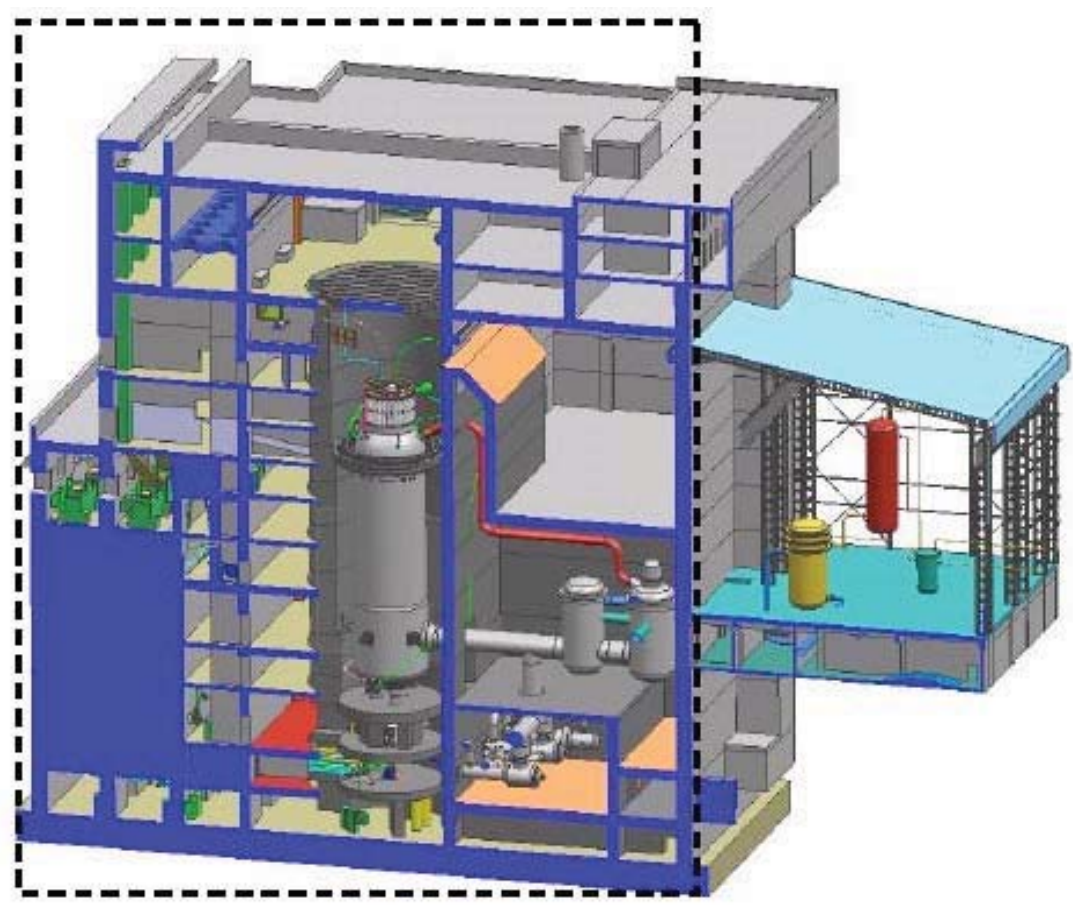

Figure 1: Cross-sectional View of 165 MWe PBMR Reactor Building (Source - PBMR Ltd., ca. 2008)

The fuel would be more highly enriched than typical LWR fuel, being on the order of $9.6 \%$ U-235, although the uranium content per sphere is miniscule at 9 grams. The fuel spheres are approximately the size and shape of tennis balls. In the 165 MWe design, the reactor core would have approximately 452,000 fuel sphere "pebbles," containing approximately 5.5 significant quantities (SQ) ${ }^{\text {b }}$ of U-235 in the form of low-enriched uranium (LEU) and 5.3 significant quantities of plutonium. ${ }^{21}$ Fuel is continuously added and drained from the reactor core at steady-state, at the rate of approximately 500 pebbles per day.

\footnotetext{
${ }^{b}$ The significant quantity (SQ) is a quantity defined by the International Atomic Energy Agency (IAEA) that represents approximately the amount of fissile nuclear material required to fabricate a simple atom bomb and accounts for material lost in the chemical conversion and machining steps. An SQ of low-enriched uranium (U-235 $<$ than $20 \%$ ), is $75 \mathrm{~kg}$ of U-235 in the form of LEU. An SQ of plutonium is $8 \mathrm{~kg}$.
} 
The following is a detailed technical description of the South African PBMR feed and core fuel transfer, as excerpted from Reference-19, based on the 165 MWe PBMR design:

The core contains nominally 452,000 spheres, and loading is done on-line. Fuel is introduced into the core through three lines at the top of the reactor, and is extracted from the reactor through three defueling chutes at the bottom. Each of the defueling chutes leads to a Core Unloading Device (CUD), where the spheres are singularized and the spheres that are broken, damaged, or have too small a diameter are removed from the lines. Following discharge from the CUD, a gross gamma activity measurement is done to identify whether it is a graphite or fuel sphere. This facility is mainly used during the period when the core contains both fuel and graphite spheres [i.e. during reactor start-up]. After the sphere type is identified by the gross gamma activity count, the spheres are transported pneumatically to the top of the reactor, where each fuel sphere is assayed for burn-up. After the burn-up is determined, the fuel is either routed to the reactor or discharged to the spent fuel tanks.

The fuel spheres will be circulated in this manner an average of 6 times to reach optimum burn-up and will then be collected in one of ten purpose-built spent-fuel storage tanks (or bins). Each of these spent-fuel storage bins would hold approximately 620,000 spent fuel pebbles. Each spent fuel pebble would contain approximately 0.12 gram plutonium; conversely, it would take 66,700 spheres to equal one SQ of plutonium. One can see at this early stage, that the diversion of one SQ of spent fuel would require a huge number of spent fuel pebbles and should be easily detected by effective containment and surveillance measures.

The reactor designers envision that the spent fuel would need to remain on site longer than the original operating design life of the reactor, which is 40 years. However, considering the modular design, it is not inconceivable that the reactors vessels could be replaced and the facility reused. In any event, the modular construction would easily permit the addition of replacement PBMRs on the same site. Under the current designs being considered, the fresh fuel and spent fuel storage bins may be shared with collocated reactors, although the number of these would probably be scaled up to provide for adequate fresh fuel storage for all of the units, and suitable storage space for spent fuel, in the event of reactor upsets at any of the operating units. Prior to loading in the reactor, the fresh fuel pebbles are stored in drums containing 1,000 pebbles, although the size of these drums could easily be changed in the future. Considering that the enrichment levels are higher than LWR fuel, constraints regarding the maximum storage volume and the absence of water or fire-protection water systems for nuclear criticality safety will impose some limits on the design of the fresh fuel storage area.

\subsection{Redesign of the PBMR - 2009}

At the time of the preparation of this report, PBMR (Pty) Ltd., announced that it was scaling down and redesigning the PBMR from a 400 MWth (165MWe) HTGR with Brayton steam cycle to a $200 \mathrm{MWth}(80 \mathrm{MWe})$ nuclear co-generation steam plant, as shown in the figure below. ${ }^{22}$ From the relative sizing of the reactor vessels, the fuel inventory would appear comparable, although the halving of the power output should also result in a significant reduction in core fuel. The feed storage and spent fuel requirements would also be cut approximately in half, commensurate with the halving of the power output. While this has a bearing on nuclear safeguards, the overall safeguards issues still depend on the bulk nature of the pebble fuel and the on-load refueling of the reactor, which have not changed. The fundamental safeguards issues are summarized in the following section. Throughout the balance of this preliminary safeguards report, we refer to the specifications and fuel handling features of the original 400 MWth (165 MWe) PBMR. Once PBMR (Pty) Ltd. describes the fuel handling and fuel inventory features of the scaled-down reactor more completely, the National Laboratory Team should update this safeguards review in a follow-on report, or addendum. Reasons for the product re-design provided by Westinghouse Electric, one of the participants in the PBMR Project, are: affordability of the smaller reactor, simplification of the reactor vessel and ancillary equipment, and focus on on-site power and steam co-generation with direct process heat applications. 


\section{Revised Product Strategy}

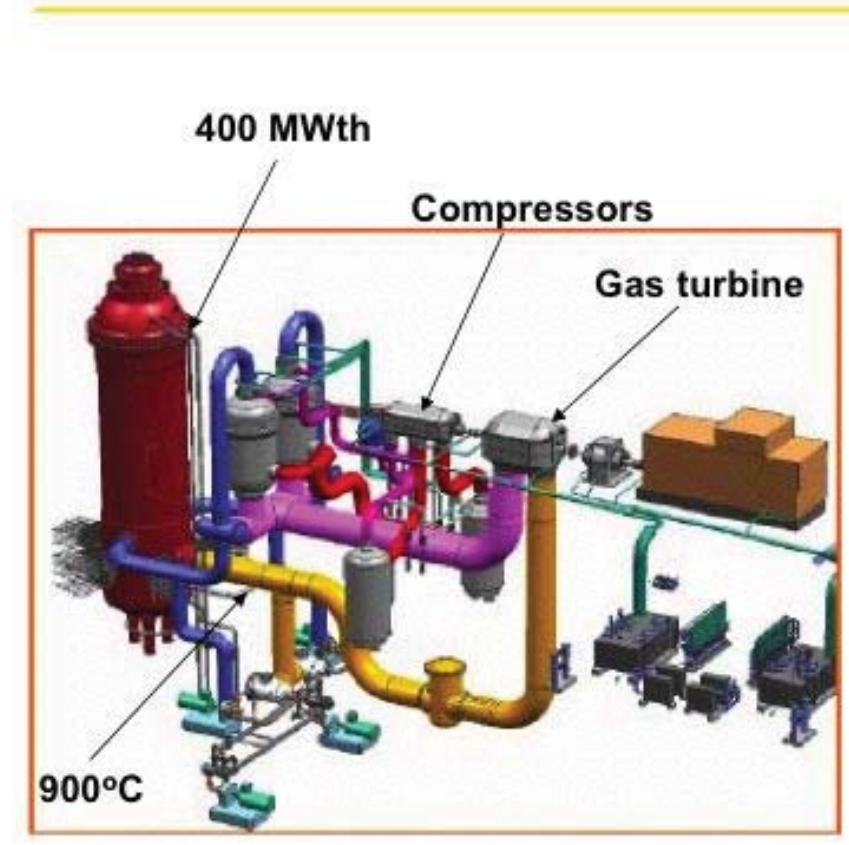

Brayton Cycle Electric Plant

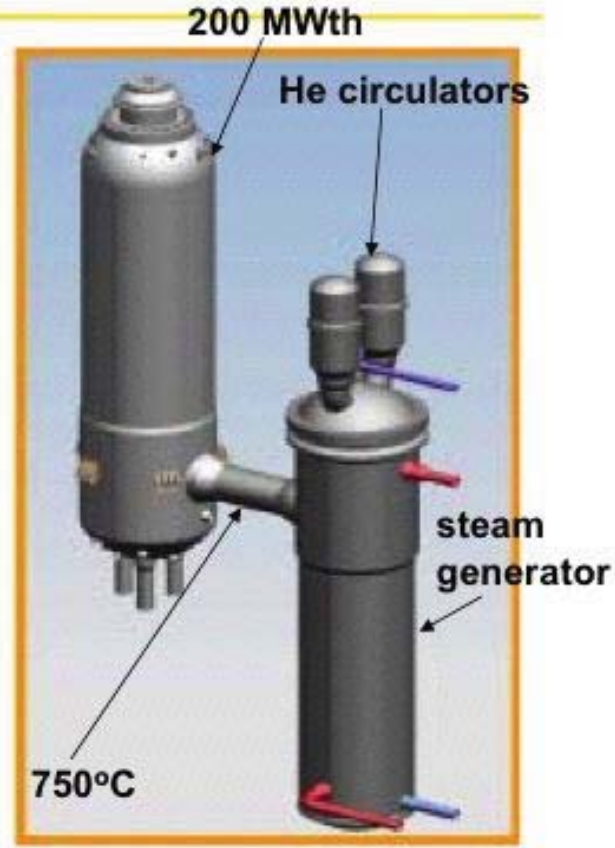

Cogeneration Steam Plant

Figure 2: Redesign of the PBMR - From 400 MWth to 200 MWth with Cogeneration (Source Westinghouse Electric Co., June, 2009)

\subsection{The New Reactor Needs a New Safeguards Approach}

The National Laboratory Team and the IAEA have noted that this type of reactor does not fit the typical cases in the current IAEA Safeguards Criteria, under the categories of light-water reactor (LWR), on-load refueled reactor (OLR), or other-types of reactor (for example, HTGR). ${ }^{23}$ To safeguard these reactors under the current safeguards criteria, the IAEA would need to uniquely identify the fuel items and randomly verify fresh fuel to confirm uranium and/or plutonium content, and verify that the spent fuel is highly irradiated. What is then clear from the outset of this discussion is that this is not practical, considering that the nuclear fuel is dispersed among a huge number of fuel pebbles. Safeguarding the PBMR appears to be more similar to safeguarding an enriched uranium or MOX fuel fabrication plant, where the mass, uranium, U-235, and/or plutonium content of the bulk nuclear material is verified by non-destructive and destructive assay. Consequently, there is a need to consider a safeguards criteria and approach more suited specifically to the PBMR, which is the focus of the following study.

The safeguards approach needs to consider the unique features of the PBMR, in addition to the usual issues of safeguarding fresh, core, and spent fuel. The fresh fuel contains $9.6 \% \mathrm{U}-235$, although the amount of U-235 per sphere is small. Regardless, it must be possible to verify the bulk mass or volume of the fresh fuel, take pebble samples, or verify the enrichment of the fresh fuel using non-destructive assay (NDA), and positively verify from which drum or bin it comes. Considering the large bulk of fuel-bearing material in the core, in principle, it is possible to introduce, irradiate and discharge pebbles, for the 
undeclared irradiation and production of plutonium. In contrast to LWRs, the core cannot be viewed during refueling over the 40 year life of the reactor, although the IAEA currently faces this same issue in safeguarding the CANDU reactor. Only bulk verification of the core and the spent-fuel bins appears possible, although destructive and non-destructive assay (DA and NDA) verification of sample materials from both would help confirm the absence of substitution of spent fuel with non-fuel items. It appears that the spent fuel can only be verified by a combination of flow monitoring, spent fuel counting and NDA as noted. There will also be storage bins and transfer routes for non-fuel graphite pebbles and damaged pebbles and a transfer route for pebbles for post-irradiation examination (PIE). Consequently, there will be nuclear material diversion routes that have not been encountered in power production reactors.

The nuclear material diversion scenarios can be summarized in general as:

- Diversion and removal of spent fuel pebbles, containing irradiated plutonium, from the spentfuel storage bins, or as redirected from the core

- Diversion and removal of partially-spent fuel pebbles, containing irradiated plutonium and U-235, during recirculation from the core

- Diversion and removal of fresh fuel pebbles, containing unirradiated U 235 in the form of LEU, from feed drums or fresh fuel storage bins

- Misuse of the PBMR for undeclared feed, irradiation, and withdrawal of spent fuel pebbles for producing plutonium or $\mathrm{U} 233$.

While in principle, all of these scenarios are possible, the would-be diverter would need to remove a huge number of pebbles in all cases to come close to diverting an SQ of U-235, plutonium, and/or thorium. These safeguards issues will be addressed in more detail in following sections of the report. 


\section{INTERNATIONAL NUCLEAR SAFEGUARDS REQUIREMENTS 2.1 Traditional Nuclear Safeguards}

The IAEA currently places the PMBR in the category described in the Safeguards Criteria as "Other Types of Reactors," a miscellaneous category that generically includes high temperature reactors and other advanced experimental designs. ${ }^{24}$ Although the PBMR presents safeguards challenges, because of the continuous on-load refueling, defueling, and recirculation of the pebble fuel; a huge amount of pebbles would need to be diverted to divert an SQ of uranium, plutonium, and/or thorium. Also, these types of safeguards challenges have been effectively addressed in the past in safeguarding research reactors and on-load refueled (CANDU-type) reactors.

The two principal safeguards concerns at PBMRs are:

- Production and diversion of an SQ of plutonium from the PBMR core and/or spent fuel storage defined as $8 \mathrm{~kg}$ of plutonium (Pu-238 less than $80 \%$ of total $\mathrm{Pu}$ )

- Diversion of an SQ of U-235 from the fresh, core, or spent PBMR fuel - defined as $75 \mathrm{~kg}$ of U-235 in the form of low-enriched uranium (LEU). ${ }^{25}$

Of these two main concerns, the production and diversion of $\mathrm{Pu}$ from the core and spent fuel is probably of more immediate concern, because of the smaller number of fuel spheres required to divert an $\mathrm{SQ}$, and because the timeliness for detection is only three months for irradiated plutonium, as opposed to one year for low-enriched uranium. In this regard, there are two possible scenarios: i) to divert core or spent fuel and route for undeclared removal and separation of plutonium at a clandestine reprocessing facility, or ii) to irradiate and divert specially designed natural uranium target fuel concealed in the normal input to the reactor to produce plutonium for subsequent removal and separation at a clandestine reprocessing facility. In the latter case, the target fuel could potentially be undersized or altered to permit easier identification and collection by the would-be diverter.

Regarding the potential diversion of fresh or slightly irradiated fuel to recover U-235, there are two scenarios: i) to fuel a clandestine plutonium production reactor, or ii) to feed a clandestine uranium conversion and enrichment plant. A would-be proliferator would gain a significant advantage and headstart using 9.6\% enriched uranium over natural uranium to feed a clandestine uranium enrichment plant to produce weapons grade uranium (ca. 90\% U-235). However, the difficulty of removing and processing the large number of pebbles (90,000 or more) to gain an SQ of U-235 makes this a more challenging diversion scenario and provides a means for detection, if effective containment and surveillance measures are utilized.

The international nuclear safeguards objectives stem from the technical goals of IAEA safeguards summed up in the IAEA Model Safeguards Agreement, INFCIRC/153 (corrected) as: ${ }^{26}$

...the objective of safeguards is the timely detection of diversion of significant quantities of nuclear material from peaceful nuclear activities to the manufacture of nuclear weapons or of other nuclear explosive devices, or for purposes unknown, and deterrence of such diversion by the risk of early detection. [Emphasis added]

Phrases are highlighted to emphasize the fundamental goals of international safeguards, being:

- Timely detection

- Significant quantities of nuclear material

- Deterrence by risk of early detection. 


\subsection{Timely Detection Goals}

The timeliness goals for detecting a diversion of LEU or plutonium are defined by the IAEA and are based on the time required to produce a crude atom bomb from either of these materials. These timeliness goals for detection are shown in Table 2. Note that these are the timeliness goals under traditional international safeguards. In many countries where the PBMR would be considered, these would be relevant. However, if the IAEA has implemented Integrated Safeguards in the country in question, oftentimes the timeliness goals are relaxed, because additional safeguards measures are used to evaluate safeguards in the country as a whole. In the case of spent fuel, the timeliness could change from three months to one year, based on previous cases.

Table 2: IAEA Timeliness Goals for Detecting Diversions of PBMR Nuclear Materials (Source - IAEA Safeguards Glossary - 2001)

\begin{tabular}{|l|l|}
\hline Nuclear Material & Detection Timeliness Goal \\
\hline Pu in core or spent fuel (Irradiated direct-use material) & 3 Months \\
\hline U containing $<20 \%$ U-235 (LEU) & 1 Year \\
\hline
\end{tabular}

\subsubsection{Detection Quantity Goal}

The detection quantity goals for uranium and plutonium in a PBMR are the aforementioned SQ values, shown in Table 3. For uranium in the form of LEU, this is $75 \mathrm{~kg}$ of U-235, and for plutonium, this is $8 \mathrm{~kg}$.

Table 3: Relevant IAEA Detection Quantity Goals or a PBMR (Source - IAEA Safeguards Glossary, 2001)

\begin{tabular}{|l|l|}
\hline Nuclear Material & Detection Quantity Goal \\
\hline U containing $<20 \%$ U-235 (LEU) & $75 \mathrm{~kg}$ of U-235 \\
\hline Natural Uranium & $\begin{array}{l}10 \text { tonnes of natural uranium } \\
\text { (i.e. approximately } 75 \mathrm{~kg} \text { of U-235) }\end{array}$ \\
\hline $\mathrm{Pu}$ & $8 \mathrm{~kg}$ \\
\hline
\end{tabular}

\subsubsection{Deterrence by Risk of Early Detection - Probability of Detection Goals}

Once the timeliness and quantity goals for the nuclear material are defined, one can determine the safeguards measures needed for a given probability of detection. Table 4 lists these detection probabilities as defined by the IAEA Safeguards Criteria, under "Other Types of Reactors," for both INFCIRC/153 and INFCIRC/66 ${ }^{\mathrm{c}}$ safeguards agreements. ${ }^{27,28}$ However, if the IAEA is permitted to use the strengthened safeguards measures provided under the Additional Protocol (AP), and has implemented an integrated state-level safeguards approach in the country (i.e. Integrated Safeguards), the detection probability may be relaxed. Based on precedents, the detection probability could potentially be reduced to $10 \%$, if the country were under Integrated Safeguards.

\footnotetext{
${ }^{c}$ The INFCIRC/66 is an older IAEA Safeguards Agreement developed in the 1960s and is in force only in India, Pakistan and Israel. It has generally been superseded by the Model Comprehensive Safeguards Agreement (INFCIRC/153), and where possible, enhanced with the Additional Protocol (AP). It is mentioned only for completeness, since there is the possibility that the PBMR could be marketed and constructed in these three countries.
} 
An evaluation of the PBMR reactor fuel cycle and expected nuclear material composition of the fuel, performed by researchers at the INL, is shown in Table 5, indicating how many pebbles would be required for the diversion of a significant quantity of LEU or plutonium in the form of fresh, core, or spent PBMR fuel. ${ }^{29}$

Table 4: IAEA Specified Probabilities for Detecting Diversions of Nuclear Material Relevant to a PBMR (Source - IAEA Safeguards Criteria, Other Reactors, 2003)

\begin{tabular}{|l|l|}
\hline Nuclear Material & Detection Probability \\
\hline U containing $<20 \%$ U-235 (LEU) & $50 \%$ \\
\hline $\mathrm{Pu}$ & $50 \%$ \\
\hline
\end{tabular}

Table 5: PBMR Fuel Pebble Composition \& Number of Pebbles per Significant Quantity (SQ) (Source Todd et al., INL, 2006)

\begin{tabular}{|c|c|c|c|c|c|c|c|c|}
\hline PBMR Fuel Pebble & \begin{tabular}{|c|}
$\mathrm{U}-235$ \\
Enrich. \%
\end{tabular} & \begin{tabular}{|l|} 
U-238 \\
grams
\end{tabular} & $\begin{array}{l}\mathrm{U}-235 \\
\text { grams }\end{array}$ & SQ LEU & $\begin{array}{c}\text { Pu } \\
\text { grams }\end{array}$ & SQ Pu & $\begin{array}{c}\text { Pebbles per } \\
\text { SQ-LEU }\end{array}$ & $\begin{array}{c}\text { Pebbles per } \\
\text { SQ-Pu }\end{array}$ \\
\hline Fresh Fuel (FF) & 9.6 & 8.134 & 0.864 & $1.2 \times 10^{-5}$ & 0 & 0 & 86,800 & N.A. \\
\hline $\begin{array}{c}\text { Core Fuel* }(\mathrm{CF}) \\
*(\text { Assumes average of fresh and spent fuel) }\end{array}$ & 6.23 & 7.887 & 0.530 & $7.1 \times 10^{-6}$ & 0.077 & $\begin{array}{l}9.7 \mathrm{x} \\
10^{-6} \\
\end{array}$ & 141,500 & 104,000 \\
\hline Spent Fuel (SF) & 2.50 & 7.835 & 0.196 & $2.6 \times 10^{-6}$ & 0.154 & $\begin{array}{l}1.9 \mathrm{x} \\
10^{-5} \\
\end{array}$ & 382,700 & 52,000 \\
\hline
\end{tabular}

Herring, et al., at the Los Alamos National Laboratory (LANL), have estimated that if special $\mathrm{UO}_{2}$ target spheres were inserted into the PBMR to produce weapons grade plutonium, the number of spent fuel pebbles could be reduced from ca. 50,000 to 20,000 for the diversion of an SQ of plutonium. However, these targets would need to be optimized for plutonium production and could be potentially detected in the random verification of fresh fuel. ${ }^{30}$ In any event, a huge number of fuel pebbles would need to be diverted, although fewer in the case of the plutonium diversion path than in the case of the LEU diversion route.

The IAEA used the defined detection goals for timeliness, quantity, and probability and developed safeguards criteria for Other Types of Reactors, including high temperature gas reactors, and notionally PBMR. Since the nuclear material has a one year timeliness detection goal for LEU and a three-month timeliness goal for irradiated plutonium, a yearly Physical Inventory Verification (PIV) will provide sufficient timeliness for detecting diversions of LEU, but not for the plutonium. Hence, interim inventory verifications (IIV) at quarterly intervals permit timely detection of diversions of plutonium in the spent fuel storage and the core. Since the PBMR is an On-Load Refueled Reactor (OLR), in the same vein as the CANDU and RBMK, the IAEA will have to deal similarly with the verification of receipts of pebbles, continuous feeding of fresh fuel, recirculation of core fuel, and continuous discharging of spent fuel pebbles from the reactor. The safeguards inspector will have three major issues: i) verify the receipt of fresh fuel at the reactor and transferred to the core, ii) verify transfers of spent fuel from the reactor core to spent fuel storage, and iii) Verify the fresh fuel, core fuel and spent fuel inventory. These are the challenges in safeguarding an OLR in general, and the PBMR in particular, because of its hybrid nature of being in between a true "item facility" and a "bulk facility," in terms of IAEA safeguards.

The PBMR is a reactor type that defies the traditional item accountancy safeguards approach applied to LWRs. ${ }^{31}$ Reactors like the PBMR that prohibit traditional item counting fall into a safeguards gap between item-counting facilities and bulk facilities, i.e. facilities where the nuclear material is in bulk form, such as powder, pellets, or small fuel pebbles. The difficulties associated with traditional item counting have given rise to safeguard approaches that rely upon maintaining continuity of knowledge (CofK) of containment and surveillance (C/S) data throughout the operational lifetime of the reactor. This 
approach attempts to cover the frequency of inspection for timeliness. The reliance on continuity of knowledge represents an inherent vulnerability in the safeguards approach. If the continuity of knowledge were lost and could not be re-established, the facility would probably not be able to attain the IAEA timeliness detection goals for the duration of its operational lifetime and possibly not recover thereafter. Simply put, the IAEA would not be able to confirm that nuclear material had not been diverted from the facility during the period when the $\mathrm{C} / \mathrm{S}$ was lost. This would be reflected in the safeguards conclusions drawn by the IAEA for the country and indicated in the IAEA annual Safeguards Implementation Report (SIR). With this in mind, it is clear that a new safeguards approach is required for the PBMR to mitigate this vulnerability.

PBMR tennis ball-sized fuel pebbles have no external identification or markings. A research reactor, such as the HTR-10 in China, has 30,000 fuel pebbles in the core. The 165 MWe (400 MWth) PBMR Ltd. reactor will have approximately 452,000 fuel pebbles in the core. Consequently, it is impossible to apply traditional core verification techniques to the PBMR, as one would to the core of an LWR - i.e. open the reactor core missile shield during annual refueling, count the assemblies, and randomly identify and verify the gross radiation attribute (Cerenkov glow) to detect the possible undeclared substitution of core fuel with dummy assemblies.

The most probable diversion scenarios for the PBMR are: i) diversion of undeclared irradiated target fuel pebbles for producing plutonium or U-233, or ii) diversion of spent fuel pebbles from the facility. In both cases, the would-be diverter would attempt to conceal this activity in a very hectic background, involving the transfer and recirculation of thousands of fuel pebbles to and from the reactor. This would be especially challenging during the initial start-up when the reactor is half filled with moderating graphite spent fuel dummies, which would be gradually drawn down and replaced by LEU fuel pebbles, as the reactor reaches operating power and equilibrium. However, as noted above, a diversion would require 50,000 to over 100,000 fuel pebbles, or on the order of $10 \%$ of a PBMR reactor core fuel inventory. In an LWR, the diversion of two to three assemblies is enough to gain an SQ of plutonium. Hence, the loss of even 100 pebbles would be on the order of a fraction of a percent rather than multiple SQs for an LWR. Therefore, the hybrid bulk handling approach for the PBMR would be sensible, especially considering the small amount of nuclear material per fuel pebble ( $9 \mathrm{~g}$ initial uranium) and the fact that an SQ of nuclear material would typically involve 50,000 to over 100,000 fuel pebbles. In many ways, the safeguards issues for a PBMR more closely resemble those of an enriched uranium fuel fabrication plant, rather than a conventional nuclear reactor.

The verification of spent fuel pebbles is complicated by the storing of PBMR spent fuel in one of ten spent fuel storage bins that nominally could contain 620,000 spent fuel pebbles. These bins would be a high radiation area and human access would be prevented, which also precludes direct verification of the spent fuel in storage, one of the main safeguards issues with the PBMR. Traditional item counting, random item identification, and gross attribute verification, as has been applied to spent fuel at other types of reactors, including CANDU-type on-load refueled reactors, is not practical or possible in this case. However, Mr. Slabber of PBMR (Pty) Ltd. has proposed an elaborate and redundant fuel flow monitoring and containment/surveillance safeguards approach that would help address these issues. ${ }^{32}$ More will be said about this and the vulnerabilities in the next section Safeguards Technical Challenges. However, it should also be noted for the record that this kind of issue is not unlike the verification of U-235 bearing nuclear material or plutonium bearing nuclear material in an MOX fuel fabrication plant, which has been successfully addressed by the IAEA. As long as the IAEA has the ability to verify the bulk of the spent fuel in storage, through the use of radiation-based volume or fill-height measuring devices, the accumulation and inventory of spent fuel pebbles could be effectively monitored over the course of the reactor's life.

Regarding the nuclear material attractiveness issue, notionally the isotopic content could be attractive to a would-be proliferator. The fresh fuel would contain from 5.7 to $9.6 \% \mathrm{U}-235$, although in very small amounts, totaling 9 grams of uranium per fresh pebble. This uranium is tightly bound by a propriety 
TRISO fuel kernel process, which produces a dispersion of $\mathrm{UO}_{2}$ seeds covered by impenetrable carbide and pyrolytic graphite coatings within each pebble. This nuclear material is highly refractory and very difficult, although not impossible, to chemically recover. The spent fuel would contain approximately 0.12 grams of plutonium per pebble. So considering the isotopics, the fresh fuel would appear to be an attractive source of uranium for supporting a clandestine uranium enrichment plant. However, this uranium is exceedingly difficult to recover and it would require 87 drums of fresh fuel to achieve $1 \mathrm{SQ}$, based on the typical feed drum containing 1000 pebbles. ${ }^{33,34}$

\subsubsection{Fresh Fuel}

As noted in Table 4, the fresh fuel (FF) contains approximately $1.2 \times 10^{-5} \mathrm{SQs}$ of U-235. This table gives us an overview of the value to a proliferator of a pebble of PBMR fuel and provides perspective for the effort needed to safeguard a PBMR. The technologies expected to be used in PBMR inspections will briefly be noted in this section and described in depth in the next section.

The fresh fuel needs to be verified upon receipt from the fuel vendor, prior to loading in the reactor. The inspectors would verify the fresh fuel by counting the fresh fuel drums, weighing selected drums to confirm bulk pebble weight, and verifying uranium and U-235\% content in samples of pebbles, by nondestructive and/or destructive assay (NDA and DA). The most likely arrangement of the Material Balance Area (MBA), with probable inventory and flow key measurement points (KMP), is shown in Figure 3. In this diagram, the fresh fuel inventory is located in KMP-A, the core is in KMP-B, and the spent fuel is in KMP-C - a very typical arrangement for a nuclear reactor under IAEA safeguards. KMP-1, 2, and 3 are the fuel receipt, fuel transfer from core to spent fuel storage, and fuel shipment KMPs, respectively. Because of the number of paths for moving spent fuel pebbles, there are more flow and inventory key measurement points than one would find in an LWR, but comparable to large test reactors with postirradiation examination (PIE) hot-cells.

The operator will store the fresh fuel in a storage room after receipt in shipping barrels, which may also have been verified at the fuel fabrication plant and placed under seal. The inspectors would verify the seals on the drum (if shipped sealed) and verify the barrels at the PIV by item counting the barrels and remeasuring the pebbles in the drums with a $10 \%$ detection (random low) probability for gross defects. For fuel receipts, the detection probability would be increased to $50 \%$ (random medium), and the sampling plan increased accordingly. The pebbles would be verified in randomly selected drums to confirm uranium and U-235 content. The number and random selection of the drums would be based on the IAEA's random sampling plan and algorithm. ${ }^{35}$ The verification of the fresh fuel in drums should be possible using the IAEA HM-5 detector or mini multi-channel analyzer (MMCA) coupled with a cadmium-telluride, sodium, or germanium detector. ${ }^{36}$

\subsubsection{Core Fuel}

The core fuel in an OLR poses the safeguards challenge of being inaccessible to visual or NDA verification. The core fuel in the PBMR is shown in KMP-B in Figure 3. The operator loads the fresh fuel pebbles into the PBMR fueling machine, which fills fresh fuel into the core to the proper fuel height. The fuel pebbles migrate downward through the core until they drop out of the bottom and are checked by the Core Unloading Device (CUD) for being either fuel or a non-fuel item (such as start-up graphite moderator pebbles) and for burnup, based on gamma assay. This occurs at the nuclear material flow key measurement point KMP-2. Non-fuel items are removed as the core reaches equilibrium, while fuel pebbles move through the core and are recirculated to achieve a pre-determined burnup, which has been estimated by modeling to be six passes on the average. 


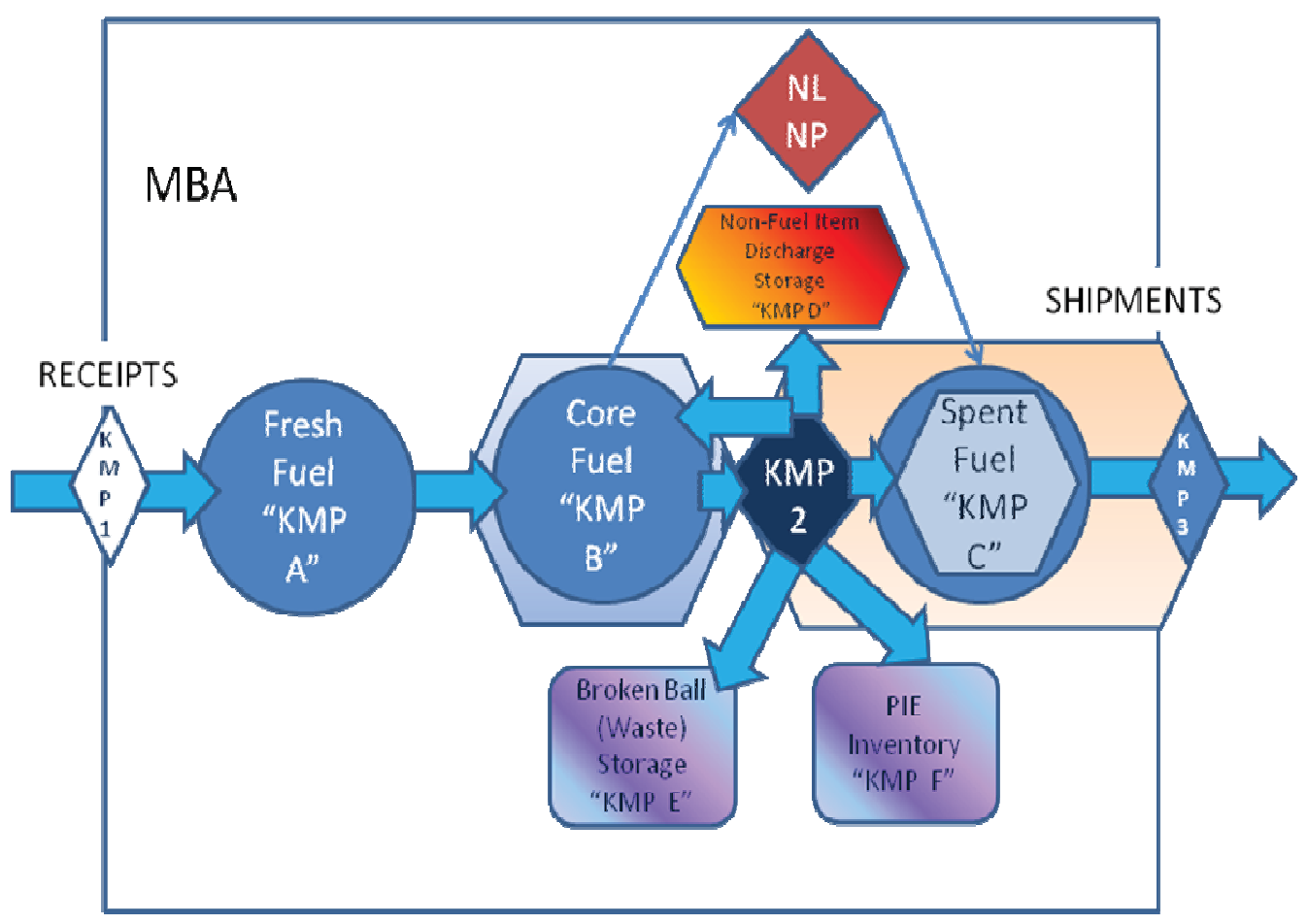

Figure 3: Proposed Nuclear Material Balance Area (MBA) and Key Measurement Points (KMP) for the PBMR (NL=Nuclear Decay (Loss), NP = Nuclear Production, PIE = Post Irradiation Examination) (Source - Los Alamos National Laboratory)

Depending on the burnup, the pebbles are routed to the proper loading position in the core or ejected as spent fuel to KMP-C. If damage is detected, the pebbles are sent to the broken ball waste storage (KMP-E). If individual fuel pebble transfers were declared by the operator, they would need to declare and account for an average of 500 fresh fuel pebbles loaded and 2900 recirculated per day, which would need to be verified by the spent fuel pebble counter/flow monitor - i.e. about one every 30 seconds. Clearly, the declaration and accounting of such large numbers of fuel pebbles individually would be onerous. Direct observation of the pebbles also seems out of the question, due to the high radiation field.

The PBMR core would contain approximately 4 SQs of LEU and 5 SQs of plutonium in 450,000 pebbles, based on the average burn-up of $45,000 \mathrm{MWd} / \mathrm{t} .{ }^{37}$ The IAEA Safeguards Criteria for such a difficult-to-access core requires dual C/S measures to ensure no unrecorded removal of fuel. Dual C/S is defined by the IAEA as follows: ${ }^{38}$

In a dual C/S system, each plausible diversion path is covered by two C/S devices that are functionally independent and are not subject to a common tampering or failure mode...e.g. two different types of seal, or seals plus surveillance. Dual C/S is normally applied where the verification of nuclear material is difficult to perform, in order to increase confidence in the C/S results and reduce the requirements for periodic re-verification.

The purpose of the dual $\mathrm{C} / \mathrm{S}$ is to verify the absence of undeclared removal of spent fuel. Considering that the fuel will be in numerous small fuel pebbles, it may be possible to sample the core fuel using the PIE fuel transfer system, in order to verify the average burn-up in the core. It may also be possible to use the operator's instruments, or other independent power monitors, to determine the power output of the reactor to estimate the amount of nuclear material present in the core. If fuel counters are employed, they would be used to determine the approximate number of fuel pebbles transferred to, from, and remaining in the core. 


\subsubsection{Spent Fuel}

The PBMR will present the IAEA with enormous numbers of spent fuel pebbles for random verification. At equilibrium, 500 spent fuel pebbles will leave the reactor and transfer to one of ten spent fuel storage bins, which can contain 620,000 pebbles each. Broken or damaged fuel pebbles will be transferred to KMP-E. Pebbles selected for burn-up and post-irradiation examination (PIE) will be sent to KMP-F. Consequently, there are two more diversion pathways in a PBMR than normally encountered in an LWR. Since a waste stream similar to that in a bulk handling facility exists, the idea of a hybridized item/bulk facility safeguards approach would appear appropriate. Verification of KMP-D, E, and F, would be required at the time of the PIV to confirm the absence of undeclared transfers and inventory of spent fuel pebbles at these locations. KMP-F is likely to include a hot-cell for taking samples of fuel for post-irradiation examination (PIE). If that is the case, it is likely that an inspector will be able to view inside the hot cell to confirm whether there is PBMR fuel present. Verifying KMP-D (Graphite Pebbles) and KMP-E (Broken Pebble Storage) will be more challenging, because these bins will be collocated near the spent fuel storage bins. However, if they are fitted with instrument tubes, as will be the spent fuel storage bins, it should be possible to verify them in the same manner as the spent fuel bins to ensure that they do not contain significant amounts of spent fuel. This will be discussed in more detail in Section 3.

PBMR spent fuel pebbles would contain more highly burned or lower grade plutonium, called MOXgrade in the reference noted, as compared to plutonium in spent LWR fuel assemblies. ${ }^{39}$ As noted above in Table 5, it would take 52,000 PBMR spent fuel pebbles to make one SQ of plutonium. Figure 1 shows spent fuel in KMP-C. Continuity of knowledge is maintained over the spent fuel after it leaves the reactor and arrives in spent fuel storage, to detect possible diversion. Surveillance of spent fuel storage would help provide assurance that no spent fuel has been diverted. During the PIV and interim inspections, the inspectors would verify that the $\mathrm{C} / \mathrm{S}$ systems have been effective and continuity of knowledge has been maintained on the spent fuel, and would randomly verify the fill height (volume) and gross radiation attributes of the spent fuel bins by non-destructive assay (NDA), using instrument tubes installed in each spent fuel storage bin. More will be said about the safeguards measures and recommended combinations thereof in Sections 3 and 4. Verification of the spent fuel bin s would be at the level of random medium detection probability (i.e. $50 \%$ ).

\subsection{Summary of PBMR Fundamental Safeguards Issues}

The PBMR poses some interesting nuclear safeguards challenges. The reactor holds hundreds of thousands of small fuel spheres containing gram-quantities of nuclear material that are not uniquely identifiable. Consequently, a traditional safeguards approach for "item facilities," such as LWRs, is not practical for this type of reactor. ${ }^{40}$ The IAEA model safeguards approach for the PBMR is still under development, but is presently based on maintaining the continuity-of-knowledge of the fresh, core, and spent fuel by flow monitoring and number balancing - i.e. counting the fuel pebbles that go in and out of the reactor. However, this approach is not ideal, as there is no technical means of recovering the continuity-of-knowledge (and closing the number balance) if the containment/surveillance systems fail. Table 6 below follows the proposed MBA and KMP structure proposed in Figure 3, and indicates safeguards verification measures under Traditional Safeguards, as well as the diversion threat addressed. Tentative and prospective safeguards needs are noted, which will be addressed in more detail in this report. 
Table 6: Proposed Verification Measures by KMP with Diversion Threats

(Color coded to MBA Diagram, Figure 3) (Source - Idaho and Los Alamos National Laboratory, 2009)

KMP-1: Flow-KMP, Fresh Fuel Receipts

Verification of Shipper's declaration for number of fresh fuel drums, ID, and random gross-weight verification. Random verification by non-destructive or destructive assay (NDA or DA) for uranium and U-235 content. Random verification detection probability medium (50\%).

Threat - Diversion of fresh fuel and substitution with non-fuel items (for example, graphite moderator).

Notes - May need to take representative samples for DA (uranium and U-235 content).

KMP-A: Inventory KMP, Fresh Fuel Storage

Verification of stored fresh fuel drums by item counting, ID check, and random verification of gross weight. Random verification by non-destructive or destructive assay (NDA or DA) for uranium and U-235 content. Random medium detection probability (50\%). Comparison with the operator's records and fresh-fuel-flow monitor regarding the number of fresh fuel pebbles fed to the reactor core.

Threat - Diversion of fresh fuel and substitution with non-fuel items (for example, graphite moderator).

Notes - May need to take representative samples for DA (uranium and U-235 content).

KMP-B: Inventory KMP, Reactor Core

Verification of effective dual containment and surveillance measures (seals and video surveillance). Verification of fuel-flow monitor/pebble counters to estimate number of spent fuel pebbles fed to and removed from reactor core, and comparison with the operator's declaration and operating records. Verification of reactor power output, using independent power monitor. Possible sampling of reactor core for average burn-up using the post-irradiation examination fuel sampling hot-cell and system. Estimate of Pu and U-235 content in core based on burn-up software code (for example, ORIGEN) Threat - Diversion of core fuel, and/or undeclared introduction of specially designed fuel for target irradiation.

Notes - Burn-up software codes for PBMR have not been well benchmarked. Effective use of a fuel flow monitor/pebble counter for thousands of fuel pebbles has not yet been demonstrated.

KMP-2: Flow KMP, Spent Fuel Transfer (and Nuclear Loss and Production)

Verification of effective dual containment and surveillance measures (seals and video surveillance). Verification of fuel-flow monitor/pebble counters to estimate number of spent fuel pebbles fed to and removed from reactor core, and comparison with Operator's declaration and operating records. Possible sampling of spent fuel for average burn-up using the post-irradiation examination fuel sampling hot cell and system. Estimate of Pu and U-235 content in spent fuel and Nuclear Loss (decay) and Nuclear Production based on burn-up software code (for example, ORIGEN)

Threat - Diversion of spent fuel and possible substitution with dummies (for example, graphite balls), and/or undeclared removal of specially designed fuel for target irradiation.

Notes - Burn-up software codes for PBMR have not been well benchmarked. Effective use of a fuelflow monitor/pebble counter for thousands of fuel pebbles has not yet been demonstrated. Need to verify numerous spent-fuel transfer paths during Design Information Verification (DIV). Need to independently verify spent fuel by non-destructive assay.

KMP-C: Inventory KMP, Spent Fuel Storage

Verification of number of spent fuel pebbles in storage by corroborating fuel-flow monitor/pebble counter with operator's declaration regarding spent fuel transferred to storage. Verification of fillheight in storage bins and random verification of spent-fuel gross radiation attributes, using IAEA instruments and pre-installed instrument tubes in spent-fuel storage bins. Verification of spent-fuel bins 
is at random medium detection probability (50\%) at the time of the PIV. Also, coincident verification of KMP-E (Broken Ball Storage), KMP-D (Graphite Ball Storage), and KMP-F (Post-Irradiation Sample and Prep Location) to detect "borrowing" or undeclared transfer of nuclear fuel. Spent fuel isotopic composition predicted based on burn-up code, like ORIGEN. Verification of C/S measures monitoring access to the spent fuel storage and transfer routes.

Threat - Diversion of spent fuel and possible substitution with dummies (for example, graphite balls), and/or undeclared removal of specially designed fuel for target irradiation.

Notes - Burn-up software codes for PBMR have not been well benchmarked. Effective use of a fuelflow monitor/pebble counter for thousands of fuel pebbles has not yet been demonstrated. Need to verify numerous spent fuel transfer paths during Design Information Verification (DIV). Need to independently verify spent fuel by non-destructive assay. Need to verify spent-fuel storage bin instrument tubes during DIV.

\section{KMP-3: Flow KMP, Spent Fuel Shipping}

Verification of number and ID of shipping casks. Random verification of shipping cask for gross radiation attribute of spent fuel at random medium detection probability $(50 \%)$. Comparison with the operator's declaration and records for shipment of spent fuel. Possible verification of spent-fuel storage bin fill height (before and after transfer to shipping cask) and by NDA for gross radiation attribute to verify spent fuel being shipped off-site. Verification of C/S (video surveillance) to confirm number of shipping casks and to detect undeclared shipping.

Threat - Diversion of spent fuel and possible substitution with dummies (for example, graphite balls), and/or undeclared removal of specially designed fuel for target irradiation.

Need to independently verify spent fuel by non-destructive assay. Need to verify spent-fuel storage bin instrument tubes during DIV. Under current designs, the spent fuel is expected to remain on-site for the life of the facility. Provisions for verifying spent fuel shipments are presented only for completeness.

KMP-D: Inventory KMP, Non-Fuel Items (Graphite Moderator Storage)

At the time of the PIV, verification of the graphite-storage bin for fill height and by non-destructive assay to detect possible undeclared storage of spent fuel.

Threat - Diversion of spent fuel and possible substitution with dummies (for example, graphite balls), and/or undeclared removal of specially designed fuel for target irradiation, and storage in Graphite Ball Storage.

Need capability to independently verify graphite storage bin by non-destructive assay and fill height. Designer needs to consider placement of instrument tubes in used-fuel and graphite storage bins, in the manner similar to the spent-fuel storage. Need to verify graphite storage bin instrument tubes during DIV.

KMP-E: Inventory KMP, Broken Ball Storage (Damaged Pebbles)

At the time of the PIV, verification of broken-ball storage for fill height and by non-destructive assay to detect possible undeclared removal of fuel. Verification of fuel-flow monitor/pebble counter and corroboration with operator's declaration for fuel transferred to broken-ball storage.

Threat - Diversion of spent fuel and possible substitution with dummies (for example, graphite balls), and/or undeclared removal of specially designed fuel for target irradiation, via broken-ball storage.

Need capability to independently verify broken-ball storage by non-destructive assay for radiation attribute and fill height. Designer needs to consider placement of instrument tubes inside or alongside broken-ball storage bins or drums. Need to verify broken-ball storage instrument tubes during DIV.

KMP-F: Inventory KMP, Post-Irradiation Examination (PIE) Hot Cell

At the time of the PIV, random verification of fuel in PIE hot cell and area by non-destructive assay to detect possible undeclared removal of fuel. Verification of fuel-flow monitor/pebble counter and 
corroboration with operator's declaration for fuel transferred to PIE hot cell.

Threat - Diversion of spent fuel and possible substitution with dummies (for example, graphite balls), and/or undeclared removal of specially designed fuel for target irradiation, via PIE hot cell.

Need to independently verify fuel in storage pits or positions within PIE hot cell by non-destructive assay for radiation attribute. Need to randomly item count or determine fill-height of fuel in PIE storage positions. Need to verify PIE hot cell, fuel storage pits and positions, and transfer routes during DIV.

KMP-4 (Potential), Flow KMP, Waste Transfer

Random verification of nuclear material in waste transfers at the time of transfer at a random medium detection probability (50\%) by item counting and ID checking of waste shipping containers or casks, and verification for gross radiation attribute of waste package.

Threat - Diversion of spent fuel and possible substitution with dummies (for example, graphite balls), and/or undeclared removal of specially designed fuel for target irradiation, via waste transfer.

Need proven NDA method for verifying radiation attribute of waste package from the PBMR. Designer needs to consider possible installation of waste-cask or waste-drum assay system. Waste removal routes and assay system needs to be verified during DIV.

\subsection{INFCIRC/66 Issues}

As has been noted, the INFCIRC/66 is an older IAEA Safeguards Agreement, developed in the 1960's, which is in force only in India, Pakistan, and Israel. It has largely been superseded by the Model Comprehensive Safeguards Agreement (INFCIRC/153 [corrected]), and where possible, enhanced with the Additional Protocol (AP). It is mentioned only for completeness since there is the possibility that PBMRs could be marketed and constructed in these three countries. In general, INFCIRC/66 does not allow the IAEA all of the measures necessary to implement strengthened and effective safeguards comprehensively within the country as a whole. ${ }^{41}$

We assume that the current safeguards criteria for implementing safeguards for the PBMR under "Other Types of Reactors" would be the same in a country having either an INFCIRC/66 or INFCIRC/153-type Safeguards Agreement. ${ }^{42}$ Having said that, the National Laboratory Safeguards Team reached the same conclusion as the IAEA reached previously, i.e., that the "Other Types of Reactor" category is not well suited for the PBMR. The IAEA recommended that new safeguards criteria be developed specifically for the PBMR, taking into consideration the bulk-nature of the nuclear fuel. This team endorses the IAEA's recommendation. The safeguards approach options that will be presented could be applied under either the INFCIRC/153 or the earlier INFCIRC/66 safeguards agreement. However, the former is more amenable to a state-level safeguards approach, especially where an Additional Protocol is also implemented; whereas the latter is limited to specific facilities under the agreement. The safeguards approaches that will be presented depend extensively on containment/surveillance systems and fuel flow monitors in all cases, which could be potentially enhanced with short-notice random inspections (SNRI) and remote safeguards data transmission (i.e., remote monitoring - RM). Nothing precludes this necessarily under an INFCIRC/66-type safeguards agreement. Therefore, the safeguards approach options that will be discussed could be used under that safeguards agreement as well. However, it should be noted that generally, the countries where INFCIRC/66 agreements have been implemented have not been supportive of strengthened and expanded safeguards provisions - which could potentially limit the effectiveness of the safeguards approaches in those countries. 


\section{SAFEGUARDS TECHNICAL CHALLENGES}

\subsection{Software Modeling and Simulation}

One of the challenges in designing safeguards systems for the PBMR is finding relevant data and technical specifications regarding nuclear material composition, flow, and inventory. There exists a limited ability to perform safeguards simulation and analysis of the PBMR reactor systems. Available software codes include: VSOP, ORIGEN-Juel-II, PEBBED, and ORIGEN-2 libraries generated by Eskom. ${ }^{43,44,45,46}$ The VSOP code, developed by the Jülich Research Center in Germany, is a collection of routines that has a long history of use for HTGR design work. However, the defining scripts of the PBMR are considered proprietary and are not commonly available for safeguards research purposes. ORIGENJuel II has never been made available through either RSICC or the OECD Nuclear Energy Agency (NEA) databank. The PEBBED code developed at INL is a discrete simulation of the pebble-bed core neutronics still under development and has not been released publicly. The Eskom ORIGEN libraries are considered to be proprietary commercial property. Hence, the PBMR safeguards analysis team cannot speak to the validity of the simulation results from the Eskom PBMR libraries. The DOE/NNSA Office of Nonproliferation and International Security, International Nuclear Safeguards Engagement Program (NA 242) has engaged the China Institute of Nuclear and New Energy Technology (INET) at Tsinghua University in a collaborative task to develop ORIGEN-ARP Libraries for the HTR-10 to characterize spent fuel from this reactor type. The libraries are being compared to the results of the MCNPX/CINDER simulation results to provide preliminary benchmark data comparisons. ${ }^{47}$ The development of ORIGEN libraries for the HTR-10 has also been pursued at the Oak Ridge National Laboratory. ${ }^{48}$ Realistic simulation and modeling of the PBMR to determine the nuclear material content of core fuel and spent fuel pebbles remains a significant challenge.

\subsection{Composition of PBMR Core and Spent Fuel}

Each fuel pebble is subjected to a unique time-varying neutron flux depending upon the path followed through the reactor vessel. The complexity of the fuel flow path in the PBMR system makes the modeling and computer simulation of the fuel and attendant burn-up complex as well. However, estimates of the fissile content of the core and spent fuel are available in the literature and are the basis for this subsequent safeguards analysis. Despite not knowing the exact fissile content of the core and spent fuel, the safeguards challenge remains keeping track of a large number of small pebbles in the form of fresh, core and spent fuel. A pebble that travels through the reactor vessel directly down the center-line of the core is exposed to a very different neutron flux than a pebble that traverses the reactor vessel near the outer edge. The end-of-life burnup of each pebble, expressed in percentage of initial U-235 atoms fissioned (typically $10-12 \%$ ) is quite uniform for all pebbles. Some pebbles make more passes through the vessel than others to arrive at the same end-of-life exposure. On average, six passes are required to attain this burn-up. As a result of the varying flux histories of the individual pebbles, the final composition of the pebbles can vary over a fairly wide range. A pebble that arrives at the end-of-life burnup via high neutron fluence will exhibit different attributes than a pebble of identical burnup which was exposed to lower neutron fluence. In either extreme, the final uranium and plutonium composition is nearly identical. However, the lowfluence pebble will present a higher minor actinide composition (particularly Am-241 and Cm-242) than a high-fluence pebble. A high-fluence pebble will present a larger inventory of short-lived fission products than a low-fluence pebble. Consequently, spent fuel monitoring based on gross-neutron (n) and grossgamma $(\gamma)$ measurements will observe wide variation, if the ratio of $\mathrm{n} / \gamma$ at high-fluence is much less than $\mathrm{n} / \gamma$ at low-fluence. This will be especially the case if the pebbles are measured after very short cooling times, i.e. less than six months. It is difficult to estimate the range of valid measurement results using existing modeling capabilities. As a result, it may not be possible to distinguish some core fuel from undeclared irradiated depleted uranium targets, based on gross gamma and neutron assay alone - i.e. 
detect undeclared irradiation and production using target material, by NDA. This indicates a need for developing a non-destructive assay method specifically for verifying spent PBMR fuel pebbles, which could be easily deployed with the existing PBMR design.

To better understand the composition of PBMR spent fuel, especially for benchmarking the burn-up software codes, PBMR (Pty) Ltd. is collaborating with U.S. DOE under the Next Generation Nuclear Plant Project (NGNP) and has shipped coated PBMR UO $\mathrm{U}_{2}$ fuel kernels to the U.S. DOE Idaho National Laboratory (INL) for irradiation in the Advanced Test Reactor (ATR). ${ }^{49}$ Feedback from these experiments will aid the manufacturers of the fuel in South Africa, and will help safeguards specialists and the IAEA better understand how the nuclear material content of PBMR fuel changes with burn-up and cooling time - at least in a research reactor. This will also allow updating of the burn-up codes for PBMR fuel, based on experimental feedback.

\subsection{Verification of Spent PBMR Fuel}

NA 24 has funded a study of spent fuel measurement techniques under the Next Generation Safeguards Initiative (NGSI). The objective of these studies is to identify methods of determining the plutonium composition of spent nuclear reactor fuel. A report listing various spent fuel measurement techniques under consideration in this project was recently published. ${ }^{50}$ Using this report, we can identify measurement techniques that may be applicable to the verification of PBMR spent pebbles in containers or as individual items.

PBMR pebbles can legitimately have a variable gross neutron production rate depending upon the flux history of the pebble. As the pebbles age and decay, the significant difference in neutron counts coming from Cm-242 ( $\left.\mathrm{t}_{1 / 2}=163 \mathrm{~d}\right)$ becomes less pronounced. Likewise, decay cooling reduces the differences observed in fission product gamma-ray emission. It may be possible to perform a reliable verification of 5-yr cooled pebbles using simple gross neutron and gross gamma-ray techniques to corroborate burn-up calculations of actinide content in spent pebbles. The possibility of investigating these techniques in China's research HTR-10 at Tsinghua University, Beijing, should also be considered by NA 24.

$\mathrm{X}$-Ray fluorescence (XRF) has been used to determine the ratio of $\mathrm{U} / \mathrm{Pu}$ in low-burnup spent fast breeder reactor (FBR) fuel. ${ }^{51}$ For the case of high-burnup PBMR fuel, the presence of $\mathrm{Cm}$ may be high enough, especially for fuel with short cooling time, to use XRF to determine U/Pu/Cm ratios for spent fuel. XRF measurement could also be used in conjunction with the passive neutron Albedo technique, which provides information related to the fissile/fertile isotope ratio in the spent fuel to provide a reasonable estimate of the plutonium present in spent pebbles to corroborate depletion code values. ${ }^{52}$

Active techniques may also be useful for the assay of spent PBMR pebbles. Active techniques are more expensive to deploy than passive systems and are difficult to configure for unattended operation. Nonetheless, active techniques, including differential die-away or lead slowing-down spectrometry, may provide methods of direct verification of Pu inventories of spent PBMR pebbles. ${ }^{53}$ However, the size and cost of a lead slowing-down time cave and spectrometer would most likely be prohibitive for a small facility like the PBMR.

The further study of verifying spent fuel pebbles is required, based on more precise facility design information and spent fuel composition, supported by fuel irradiation and measurement experiments, combined with fuel post-irradiation examination. The more accurate non-destructive assay of PBMR core and spent fuel remains a key issue in ensuring that the fuel and non-fuel items can be properly sorted and verified, as the safeguards approach presumes. 


\section{PBMR SAFEGUARDS APPROACHES}

\subsection{Proposed Safeguards Approaches}

The IAEA has Safeguards Criteria for "Other Types of Reactors," but they are not system specific and do not seem appropriate for a bulk-fuel reactor, like the PBMR. ${ }^{54}$ The IAEA has done preliminary internal safeguards analysis of the PBMR, however, their model safeguards approach is still under development. As was announced at the recent meeting of the United States Support Program to the IAEA in Vienna, the IAEA will not modify or further develop their model safeguards approach until the South Africans finalize their design of the PBMR, which is in flux. The IAEA projects that this design will be finalized within one to two years (ca. 2010 to 2011) ${ }^{55}$ In the meantime, PBMR (Pty) Ltd. announced that they hope to begin construction of the reactor by 2014 and operation in 2018. In any case, the safeguards approach will need to be in place by 2018, although IAEA Design Information Examination and Verification (DIE/DIV) activities will need to take place during facility construction, i.e. from 2014 onward.

The only operating pebble-bed reactor in the world is located at Tsinghua University in Beijing, China. The facility is under IAEA safeguards, however the safeguards that have been applied to date have only included fresh fuel item counting and enrichment verification. The reactor has been loaded with a pre-equilibrium core and is operated on a very low duty factor. The facility has yet to discharge any spent fuel pebbles, which is where the key safeguards challenge exists.

Safeguards at nuclear reactors are traditionally based on an item accountancy approach employing Key Measurement Points (KMPs) as described in Section 2. In this approach, fresh fuel assemblies are randomly verified to confirm the operator declarations of uranium loading, enrichment, and assembly serial number. After irradiation, the fuel is randomly measured to verify the operator declaration that the fuel is spent, typically by gross gamma-ray attribute verification - i.e. verifying the Cerenkov glow or gross gamma/neutron counting. The operator declaration of plutonium production, from depletion calculation, is accepted by the IAEA after successful attribute verification. In the case of the PBMR system, because the pebbles are not individually identifiable as they lack serial numbers or any differentiating characteristics, the traditional item approach cannot be applied. Some other method of safeguards accountancy must be used for the PBMR system.

While the IAEA has not published an open account of PBMR safeguards approaches, there are two publications in the open literature that address the issue. Bueker proposed methods for the German THTR, and Slabber proposes methods for the demonstration PBMR to be built in the Republic of South Africa ${ }^{56,57}$ Both of these approaches would employ item accountancy rather than a bulk-handling approach, focusing on fuel flow monitoring (pebble counting) as the principle accountancy technique. Consequently, the existing proposals for PBMR safeguards approaches employ ball counting (item balance) and surveillance. This is fundamentally a safeguards approach based on maintaining continuity of knowledge of the fuel flow and inventory. At first glance, this approach may appear to be adequate. However, ultimately there is the real possibility of a loss of continuity of knowledge, if the containment and surveillance systems suffer a common-mode failure, i.e. potentially a loss of main or emergency power. While this appears improbable, considering the large number of IAEA safeguards systems in use worldwide, it has happened in the past. There must be a measure in place to recover the continuity of knowledge when it is lost. Otherwise, the facility could ultimately fail to meet the IAEA quantity and timeliness goals for detection, which could result in the incident being reported publicly to the IAEA Board of Governors. Losing continuity of knowledge and the resultant non-attainment of safeguards timeliness and quantity goals is not acceptable. This has occurred at the Monju FBR in Japan, which is also an "Other Types of Reactor," although the core of Monju contains far more SQs of nuclear material than a PBMR. Because this has happened in the past, the safeguards community should learn from this unlikely event and prepare to deal with it more effectively in the future in considering the safeguards 
approach for the PBMR. If and when the continuity of knowledge number-balance pebble counting scheme fails, there needs to be some alternative means of verifying safeguarded materials in the facility.

A diagram of the safeguards approach proposed by Mr. Slabber of PBMR (Pty) Ltd. is shown in Figure 4. The approach uses fuel pebble counters (Flow Monitors - FM), surveillance cameras, and seals to provide dual containment/surveillance $(\mathrm{C} / \mathrm{S})$. This is indeed a robust application of the continuity of knowledge approach. The assumption is that if the flow monitors fail, video surveillance and seals could prove that no diversions have occurred and vice-versa. Hence, the IAEA would view this as a rather robust "Dual C/S System." However, the assumption may not be valid. The failure of the video surveillance without loss of the flow monitors does not affect the safeguards conclusion drawn from the number balance. However, the failure of the flow monitors without failure of the surveillance does not necessarily provide adequate assurance of the lack of a diversion, because identification and categorization of the spent pebbles cannot occur. It would be difficult to differentiate and account for targets, graphite balls, and spent fuel pebbles sent out to the wrong path - i.e. the broken ball path, the non-fuel item path, or the path to post-irradiation examination (PIE). Verification of the spent fuel that might have accumulated in these areas could potentially be performed to recover from the failure of the flow monitors. Adequate verification of the spent fuel bins, graphite bin, used fuel bin, and damaged pebble fuel bin would require a proven technique that has not yet been demonstrated. Also, these vessels would need to be fitted with instrument tubes, similar to the spent fuel storage bins. Similarly, reverification of the reactor core in the reactor vessel would be problematic. In principle, it is possible to pull samples of the core fuel via the post-irradiation examination sample route. However, actually verifying the amount of fuel in the core would remain challenging. Potentially this could be done by independently verifying power output at reference control rod settings, or perhaps using external radiation detectors to estimate the fill-height of fuel in the reactor core.

A second issue with this proposed approach is the lack of an independent attribute verification measurement for the spent fuel. Inspectors must make random measurement of the spent fuel pebbles to verify the operator's declaration that the fuel is spent (i.e. not substituted with dummy fuel) and potentially for estimating or corroborating plutonium production. This could be as simple as the measurement of a spent fuel attribute to corroborate the validity of a depletion code calculation, or it can be as complex as some technique for directly measuring the plutonium present in a pebble. At this time there are no off-the-shelf measurement techniques that have been shown to be suitable for verifying spent PBMR fuel.

\subsection{Review of the Number-Balance (Flow Monitor) Approach}

Individual spent pebbles have a very small plutonium inventory. Approximately 50,000 - 60,000 spent pebbles are required to make $1 \mathrm{SQ}$ of $\mathrm{Pu}$. Reliably counting and maintaining an exact number balance of some 500,000 indistinguishable items moving around the facility represents a significant challenge. Maintaining the number balance over the estimated 40-year lifespan of a facility would become even more challenging. At some point there will be errors in the counting that will give rise to a non-zero MUF (Material Unaccounted For) value, which is unacceptable in "item facilities.",

\footnotetext{
${ }^{\mathrm{d}}$ MUF is defined by the IAEA as "Material Unaccounted For." In a facility where the nuclear material accounting unit is an item, such as a fuel assembly, the assembly is either present or it isn't. Hence, this is typically called a "Zero-MUF Facility." However, in nuclear facilities where the nuclear material is handled in bulk-form, (bins of powder, trays of pellets, vats of solution) a small uncertainty arises in determining the exact amount of nuclear material present. This is the MUF. Using effective safeguards measures, this value can normally be kept very low on a percentage level, to provide assurance that no significant amounts of nuclear material have been diverted.
} 


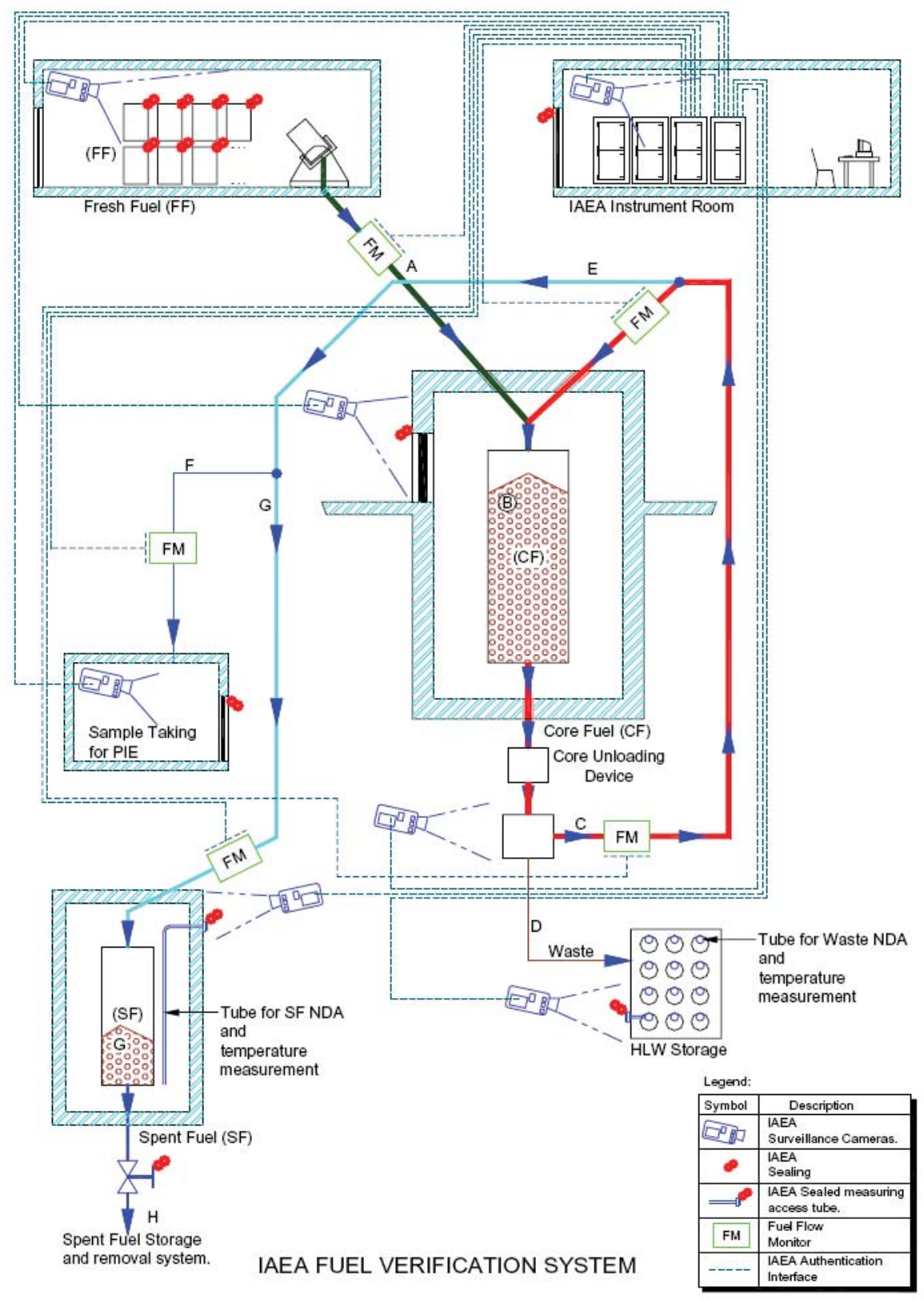

Figure 4: Schematic of the Proposed Safeguards Approach for the PBMR Showing Safeguards Measures (Source - J. Slabber, PBMR (Pty.) Ltd.)

Item facilities by definition do not accrue MUF, yet the PBMR system will indeed accrue MUF, because the nuclear material is essentially in bulk form. As such there will be some uncertainty, no matter how small, of how much nuclear material is present and in which form, i.e. how many fresh fuel, core fuel, and spent fuel pebbles. Bueker uses a unit of a "barrel," which is defined as a barrel containing 1,000 pebbles, as an accountancy unit to improve counting reliability, especially for fresh fuel. ${ }^{58}$ This is a more reasonable approach than accounting for individual pebbles, but errors on assumed packing density and inability to potentially identify irradiated $\mathrm{UO}_{2}$ targets in the barrels poses a safeguards challenge. No matter how one uses a number balance, because of the very large number of items and the long life of the 
facility, there will necessarily be some cumulative uncertainty in the counting that must be represented as MUF.

The operators of the Chinese HTR-10, which has a small core inventory of 28,000 pebbles, stated that there was uncertainty about the precise number of pebbles in the core, because the redundant facility pebble-counters did not exactly agree. ${ }^{59}$ The difference is minor and not of significant concern. However, this is the smallest PBMR core that is planned and the facility is still operating with a pre-equilibrium core. In essence, the continuity of knowledge from ball counting is already lost because the operator himself cannot provide a fixed declaration that the IAEA can verify. Reliance on ball-counting to strike a number balance is not an ideal safeguards approach. The inherent weakness of this approach is aggravated by the reality that once continuity of knowledge is lost, no technical means appears to exist to restore this safeguards knowledge, short of extensive physical inventory verification (PIV), potentially during reactor shutdown. This would be problematic to schedule, considering that the PBMR is designed to operate continuously.

\subsection{A New Bulk-Fuel Reactor Approach}

PBMR fuel pebbles are indistinguishable and sufficiently small and numerous that a PBMR is comparable to a facility handling bulk nuclear material. The amount of uranium in each pebble is comparable to the uranium in a typical LWR pellet that is loaded into pins for fabricating fuel assemblies at an LWR fuel fabrication plant. Consequently, we propose that the IAEA and PBMR operators consider a hybridized and novel bulk-handling approach for the PBMR, placing it in a new category of "Bulk-Fuel Reactors." The features of the proposed Bulk-Fuel Reactor Approach are outlined as follows: ${ }^{60}$

- Use fuel flow monitor/pebble counters to balance fuel inputs, outputs, and inventory. (Recognize that his will produce a MUF, due to counting discrepancies, broken balls, etc.).

- Use an accounting unit larger than the fuel pebble for fresh fuel, such as the fresh fuel drum. Item count fresh fuel drums, randomly check drum IDs, and randomly verify U-235 and U in fresh fuel drums using an Active Well Coincident Neutron Counter (AWCC) and weighing. (Recognize that this will produce a MUF for $U$ and U-235. Account for $U$ and U-235 in the same statistical manner as at an enrichment, fuel fabrication, or reprocessing plant).

- Randomly measure spent fuel bins to verify the gross radiation attribute of spent fuel and confirm the spent fuel fill-height and accumulation in the bin. Potentially measure samples of the spent fuel, collected via the PIE hot cell, to corroborate the fuel burnup and associated plutonium inventory. (Because existing spent fuel assay techniques cannot determine $\mathrm{Pu}$ and $\mathrm{U}$ directly, there is reliance on depletion codes in combination with verifying attribute measurement).

- Estimate the Pu and U-235 in the core fuel, based on verification of power output records, burn-up codes, and the fuel flow monitor/pebble counters.

- Use effective C/S measures (surveillance and/or seals) to detect undeclared removal of core and spent fuel.

- Draw a composite nuclear material balance from the fuel pebble number counting scheme and bulk material inventory verification. Fold the uncertainties into a composite MUF for the PBMR.

This will produce a lower MUF than either individual technique and allow a longer operating interval before MUF becomes large enough that additional safeguards verification activities might be required. The aforementioned approach is a layering of complementary safeguards measures that provide a safeguards "defense in depth" that is not possible with either the item counting (fuel flow monitoring) or bulk nuclear material verification measures alone. This approach is also amenable to continuous or random verification, whereby the fuel fed to the reactor is verified by gamma spectroscopy during 
recirculation and as it is discharged to the spent fuel bins at the existing Measurement Verification Distribution Block.

At some point the cumulative MUF statistic may approach 1 SQ of plutonium or U-235. As a result, the IAEA may request more complete physical inventory verification (PIV). This activity could potentially be coordinated during a reactor shutdown for special maintenance. Counting of fresh fuel drums and other items can be repeated to reduce errors and MUF associated with the item counting. More precise spent fuel measurements can be done on longer cooled pebbles, which could reduce the MUF associated with spent fuel verification. A statistical analysis could be performed to predict the period of reactor operation to arrive at the MUF threshold for performing this activity. In this instance, the IAEA would likely verify fresh fuel drums, spent fuel bins, PIE hot cell, Graphite Ball Storage and Broken Ball Storage at a level of random medium $(50 \%)$ or random high $(90 \%)$ detection probability. The fuel flow monitor/pebble counters and C/S systems would be verified to determine the extent of the possible MUF or safeguards anomaly. Operating records, including power output and pebble transfer records, would be compared versus the inspector's instruments and records to detect discrepancies or anomalies. The inspectors might request sampling of the reactor core via the PIE hot-cell transfer route to verify the core fuel. It is not likely that the IAEA would ever request dumping of the core fuel to the used or spent fuel storage bins, considering the cost and disruption to the facility and operator, nor is it likely that the operator and national authorities would ever accept such a request. The IAEA would have to use these other means to deduce the nuclear material remaining in the core. However, even in the worst case, this re-verification approach would be superior to the tedious accounting of every fuel pebble under the numbers balance approach, which is simply not practical.

Regarding the bulk approach, another important aspect to consider is the need to independently verify the volume or fill-height of each: spent fuel storage bin, used fuel bin, graphite storage bin, and broken fuel bin. As is shown in Figure 4, PBMR (Pty) Ltd. indicates a tube for a non-destructive assay (NDA) instrument that would traverse the height of the spent fuel storage bin. However, one would need to be provided for each bin. This would be extremely useful for confirming the fill-height and, hence, volume of the spent fuel pebbles that have been accumulated to date. Confirmation would most likely be needed during the annual PIV or during the re-verification activity noted above. This is analogous to the use of highly accurate volume or mass measuring devices on safeguarded vessels at other facilities handling nuclear material in bulk form.

The bulk approach in combination with the number-balance continuity of knowledge approach provides two independent measures of the facility MUF. The corroboration obtained by the two techniques provides safeguards assurance that neither technique can provide alone.

The layered or hybridized Bulk-Fuel Reactor safeguards approach would provide a safeguards "defense in depth," beyond fuel flow monitoring and containment/surveillance measures. These measures may provide effective safeguards without malfunction, but if the systems fail and continuity of knowledge is lost it would be extremely difficult, if not impossible, to re-establish the nuclear material flows and current inventory. Additionally, the expected variation of the core fuel uranium, plutonium, and actinide content during irradiation and recirculation makes it more difficult for the inspector to detect the undeclared irradiation of targets - since these may not be easily distinguished from low burn-up pebbles using gross gamma and neutron assay techniques. Recirculation of the fuel also makes it difficult to definitively determine what fuel has exited the reactor. An additional point to consider is the use an improved non-destructive assay technique specifically adapted for the verification of recirculating PBMR core and spent fuel, which could arise from the pebble irradiation, modeling, and spent fuel verification development work noted. Potentially, such a system could fingerprint or characterize groups of pebbles and be fully automated, being amenable to remote data transmission. If the discrimination of the system is good enough, it may be able to detect the presence or passing of undeclared target fuel pebbles, which would not be detected by gross gamma or neutrons. The on-line measurement of recirculating core fuel by more accurate assay techniques could also be used by the operator for monitoring pebble fuel burn-up and 
maintaining reactor core operating efficiency. The fact that such an on-line assay system could potentially be used by the safeguards inspector and plant operator could be sufficient motivation for the plant operator and national authorities to consider the installation of the more accurate assay system.

\subsection{Challenge of Facility Design Information Verification (DIV) for PBMR}

As discussed in the reference cited, one of the most important safeguards measures used by the IAEA today for strengthening the safeguarding of new types of nuclear facilities is the design information examination and verification activity (DIE and DIV). ${ }^{61}$ In accordance with their safeguards agreements, countries are required to provide nuclear facility design and operating information to the IAEA relevant to safeguarding the facility at the earliest stage. ${ }^{62}$ This is the case under both INFCIRC/66 and INFCIRC/153-type safeguards agreements. This provides the IAEA the opportunity to verify the safeguards relevant features of the facility and to periodically ensure that those features have not changed.

Design information for all nuclear facilities within a country is provided to the IAEA and includes:

- Identification of the facility, including general character, purpose, capacity and location

- Description of the facility layout and form, location, and flow of nuclear material

- Description of features relating to nuclear material accountancy, containment and surveillance.

Description of existing and proposed procedures for nuclear material accountancy and control, with reference to Material Balance Areas (MBA)

The design information (DI) is conveyed from the facility builder/operator through the national nuclear authorities (State System of Accounting for and Control of Nuclear Material - SSAC) to the IAEA, using the IAEA Design Information Questionnaire (DIQ). The DIQ is updated as required by written addendum submitted by the national authorities to the IAEA.

More effective use of design information examination and verification was one of the major recommendations that arose from the IAEA's 93+2 Strengthened Safeguards Program, following the revelation of a well funded undeclared uranium enrichment program discovered in Iraq, after the first Gulf War in 1991. The purpose of the facility design information examination and verification activity is to verify that the nuclear facility is as declared, with regards to name, location, function, process, and capacity. The IAEA must know these aspects in order to develop an appropriate safeguards approach and effectively safeguard the facility.

Nuclear facility design information is submitted to the IAEA in accordance with Code 3.1 of the General Part of the Subsidiary Arrangements to the State's Safeguards Agreement. Accordingly, the country must make an early declaration of any decision to construct a new nuclear facility or to modify an existing one, and provide preliminary design information on the facility. ${ }^{63}$ Table 7 summarizes the requirements to provide design information and to permit examination and verification of this information over the life of the facility. Ideally, the DIE/DIV activities should be performed and coordinated as per the Safeguards-by-Design (SBD) Process methodology described in the reference noted. ${ }^{64}$ Once the plant begins operation, the IAEA must annually re-verify that safeguards relevant changes have not been made to the facility that could potential increase the facility's capacity, change it function, or disrupt and negate installed safeguards instruments and containment/surveillance measures. The periodic re-verification of the facility and design information normally occurs during the annual physical inventory verification (PIV), but may also be performed during routine interim inventory verification (IIV), or short-notice random inspections (SNRI). 
Table 7: Nuclear Facility Life Cycle and IAEA DIE/DIV Related Activities (Source - IAEA Safeguards Manual, SMI-4.1, 2003)

\begin{tabular}{|c|c|}
\hline Facility Life Cycle Phase & IAEA-related DIE/DIV Activity \\
\hline $\begin{array}{l}\text { Design and Planning Phase } \\
\text { (Pre-Construction Phase) }\end{array}$ & $\begin{array}{l}\text { Operator Announces intention to construct a nuclear facility and } \\
\text { Provides Preliminary Design Information (DI) through the } \\
\text { national authorities (SSAC). }\end{array}$ \\
\hline Construction Phase & $\begin{array}{l}\text { Operator prepares and submits Design Information } \\
\text { Questionnaire (DIQ) through the SSAC } 180 \text { days prior to } \\
\text { construction. } \\
\text { The IAEA performs DIE/DIV during the construction phase as } \\
\text { required to ensure the facility can be adequately safeguarded. } \\
\text { More frequent DIE/DIV activities will be performed for a } \\
\text { facility of new design (such as the PBMR). }\end{array}$ \\
\hline Commissioning Phase & $\begin{array}{l}\text { The IAEA continues DIE/DIV activities, with special emphasis } \\
\text { on verifying the performance of installed safeguards monitors, } \\
\text { containment/surveillance, and remote monitoring systems during } \\
\text { Commissioning. Adequate safeguards signal authentication and } \\
\text { encryption is verified at this time. }\end{array}$ \\
\hline Operating Phase & $\begin{array}{l}\text { The facility operator updates the design information } \\
\text { questionnaire (DIQ) as safeguards relevant changes are made to } \\
\text { the plant or its declared mode of operation. These changes are } \\
\text { conveyed by written addendum through the SSAC to the IAEA. } \\
\text { The IAEA (at least) annually re-verifies the safeguards relevant } \\
\text { facility features, operation and information to detect any } \\
\text { safeguards relevant changes. }\end{array}$ \\
\hline Maintenance/Modification Phase & $\begin{array}{l}\text { The facility operator updates the design information } \\
\text { questionnaire (DIQ) as safeguards relevant changes are made to } \\
\text { the plant or mode of operation. These changes are conveyed by } \\
\text { written addendum through the SSAC to the IAEA. At a } \\
\text { minimum, the IAEA annually re-verifies the safeguards relevant } \\
\text { facility features, operation and information to detect any } \\
\text { safeguards relevant changes. }\end{array}$ \\
\hline Extended Shutdown Phase & $\begin{array}{l}\text { The facility operator updates the design information } \\
\text { questionnaire (DIQ) as safeguards relevant changes are made to } \\
\text { the plant or mode of operation. These changes are conveyed by } \\
\text { written addendum through the SSAC to the IAEA. The IAEA } \\
\text { annually re-verifies the safeguards relevant facility features, } \\
\text { operation and information to detect any safeguards relevant } \\
\text { changes. Nuclear material remains on-site or in the facility, so } \\
\text { routine inspections and DIE/DIQ activities continue, although } \\
\text { the frequency of inspection may be reduced by the IAEA as } \\
\text { allowed. }\end{array}$ \\
\hline
\end{tabular}




\begin{tabular}{|l|l|}
\hline Closed-Down Phase & $\begin{array}{l}\text { The facility operator updates the design information } \\
\text { questionnaire (DIQ) as safeguards relevant changes are made to } \\
\text { the plant or its mode of operation. These changes are conveyed } \\
\text { by written addendum through the SSAC to the IAEA. The IAEA } \\
\text { annually re-verifies the safeguards relevant facility features, } \\
\text { operation and information to detect any safeguards relevant } \\
\text { changes. The facility is typically defueled, although spent fuel } \\
\text { may remain in the spent-fuel storage bins for extended interim } \\
\text { storage. The frequency of inspection will be reduced by the } \\
\text { IAEA, as allowed, although DIE/DIV activities would still be } \\
\text { conducted annually to detect any safeguards relevant changes to } \\
\text { the secured nuclear material and/or installed instruments. }\end{array}$ \\
\hline Decommissioning Phase & $\begin{array}{l}\text { The IAEA continues DIE/DIV activities during the } \\
\text { Decommissioning Phase to verify that the nuclear facility can no } \\
\text { longer operate in any reduced or diminished capacity and that } \\
\text { any remaining nuclear material is transferred to another facility } \\
\text { that is effectively safeguarded. }\end{array}$ \\
\hline Termination of Safeguards & $\begin{array}{l}\text { IAEA verifies Decommissioned status - rights to } \\
\text { inspection/DIV terminated. }\end{array}$ \\
\hline
\end{tabular}

The need for effective DIE/DIV is stressed in particular for the case of the PBMR because:

- The PBMR is a new reactor design that the IAEA has little experience safeguarding (other than the HTR-10 in China, which is not yet at reactor equilibrium).

- The IAEA is still in the process of defining safeguards criteria more appropriate to the PBMR and Bulk-Fuel Reactors in general.

- The IAEA has not yet defined an optimized safeguards approach for the PBMR.

- The PBMR will use extensive containment/surveillance measures to monitor the flow of fuel and maintain continuity of knowledge over fuel in the inaccessible reactor core and spent fuel storage bins. Proper placement of these devices can only be effectively assessed during DIE/DIV.

- The design of the PBMR requires a number of fresh fuel feed and core fuel discharge routes that, if unchecked, could permit undeclared removal of fresh, core and spent fuel.

- The IAEA needs more experience in performing DIE/DIV at PBMRs, because it does not have extensive experience in this area, nor are operating procedures optimized for this activity.

Having said this, the IAEA has been safeguarding the HTR-10 test reactor in China for the last several years, and has made a number of technical visits to South Africa to better understand the intricate design details of the South African PBMR. One must also bear in mind that while the PBMR is a new type of modular nuclear reactor, in principle, it does not pose any safeguards challenges greater than a conventional LWR or enriched uranium fuel fabrication plant. As has been stated, a diversion of an SQ of either fresh fuel, core fuel, or spent fuel would involve the removal of tens of thousands, if not hundreds of thousands of fuel pebbles, depending on which are diverted. This should be easily detected if effective containment and surveillance measures are in place and regularly evaluated. 
Considering the proposed safeguards approach shown schematically in Figure 4, effective DIE/DIV of the PBMR should involve verification of the design, placement and performance of the following:

- Fresh Fuel bulk measuring devices (for verifying the mass or volume of stored fresh fuel)

- Flow Monitors for the fresh fuel feed, discharged core fuel, recirculated core fuel, spent fuel, and fuel samples taken for post-irradiation examination.

- $\quad$ The Core Unloading Device

- Spent Fuel non-destructive assay (NDA) and bin volume measuring system

- Bin volume measuring systems for the Unused Fuel, Graphite Pebble Storage and Broken Pebble Storage bins

- Digital Surveillance systems covering the Fresh Fuel store, access to reactor service hatch and core fuel, and the spent fuel discharge route. This includes the core unloading device, access to the spent fuel storage vaults, access to the post-irradiation examination sample hatch, access to the high-level waste store with damaged fuel, and potentially the IAEA instrument room.

- Electronic and mechanical sealing systems and tamper indicators on the fresh fuel storage drums, the reactor access hatch, access to the spent fuel storage bins, the spent fuel bin removal line and valve, access to the high level waste storage, access to the PIE sample hatch, and potentially access to the IAEA instrument room.

The authentication of the aforementioned systems would need to be confirmed, and where appropriate, the safeguards data may need to be encrypted from the safeguards sensor to the data collection computer to prevent possible interception and manipulation. An important aspect of DIE/DIV is ensuring that the safeguards instruments and equipment, instrument signals, and data collection computers have been properly secured to prevent tampering. In this regard, safeguards date authentication and where needed, encryption, are important issues and can only be easily confirmed during the DIE/DIV of the facility.

Mr. Slabber's original safeguards approach would provide redundant containment and surveillance coverage of all fuel storage and flows. It is considerably more elaborate than what is currently done to safeguard an LWR and on-load refueled (OLR, CANDU-type) reactors. This level of conservatism however, may be appropriate considering the IAEA's lack of experience in safeguarding this type of reactor. Over time, this approach could most likely be optimized. The IAEA is currently developing next generation surveillance and electronic sealing systems that would have a very prominent role in the PBMR.$^{65}$ Additionally, all of the aforementioned fuel monitors, surveillance, and electronic sealing systems are amenable to remote data transmission and monitoring (RM), as has been demonstrated by the IAEA at a number of safeguarded nuclear facilities around the world, particularly in Japan.

\subsection{Safeguards-by-Design Considerations}

Because of the unique aspects of the PBMR, the following section discusses the need to consider and incorporate nuclear safeguards design requirements at the earliest stages of the design process. Many nuclear safeguards issues have already been considered and initially addressed by PBMR (Pty.) Ltd., as is shown by Mr. Slabber's detailed schematic of proposed safeguards measures in Figure 4. However, there are additional engineering aspects that affect the ability of the IAEA to inspect and perform the design information examination and verification activities (DIE/DIV) required to detect safeguards relevant changes to the facility. The following section presents some of these issues for discussion. The National Laboratory Safeguards Team does not presume to redesign the PBMR. The following points are offered to DOE/NNSA, the IAEA, and PBMR (Pty.) Ltd. for their consideration for the sake of making the PBMR more easily safeguarded. The following discussion necessarily focuses on the design features that are available - i.e. those of the 400 MWth (165 MWe) PBMR. Knowing that PBMR (Pty.) Ltd. is in the 
process of redesigning and scaling down the reactor, the National Laboratory Team focused on safeguards relevant aspects of the general design. The reader should note however, that this aspect of the preliminary safeguards study is the most subject to revision. The safeguards relevant features of the South African 400 MWth PBMR can be found in the study performed under the U.S. DOE Generation IV design contracts, the PBMR Ltd. presentations to the U.S. NRC, and the PBMR (Pty.) Ltd. paper describing the proposed safeguards approach for the new reactor. ${ }^{66,67,68,69,70}$ The redesign of the reactor is fortuitous, because it allows the designer the opportunity to make detailed provisions for the new IAEA surveillance and containment equipment, and fuel flow monitors that have been proposed. It is also important for the designer to note that design issues relevant to nuclear safety, nuclear security, and physical protection need to be considered in tandem with nuclear safeguards requirements. In the broadest sense, "nuclear safeguards" to the public embraces nuclear safety, security (i.e., physical protection) and nuclear safeguards. It can be challenging to meet the relevant requirements, especially in the early stages of the design process. It is more typical that these requirements are met in a layered approach as they become better understood by the facility operator and designer/builder. However, if these requirements are not considered holistically at this stage, the new safeguards equipment or measures may be rendered ineffective, or it may not be possible for the IAEA to periodically re-verify the safeguards relevant design features of the facility after the facility goes "hot." This is not a new challenge for IAEA safeguards inspectors. If however, the designers of the PBMR bear this issue in mind and understand the safeguards relevant features from the perspective of the IAEA, they will be able to make these areas accessible in the future or remotely verifiable. A guide for implementing the Safeguards-by-Design process, from the standpoint of project management, is indicated in the reference noted. ${ }^{71}$

As shown in Figure 4, the PBMR has multiple flow paths for the pebble fuel, more so than in a typical LWR. The requirement is to ensure that the fuel loading and recirculation piping systems, fresh fuel storage, and spent fuel storage bins are not subject to tampering that would allow the undetected feed, withdrawal, and diversion of significant amounts of fuel pebbles. These fuel transfer routes and locations should be inspected by the IAEA during the design information examination and verification (DIE and DIV) activities, during construction and prior to start-up of the PBMR. Being able to verify the absence of undeclared feed and withdrawal of fuel is an important safeguards consideration for the PBMR, especially since the fuel pebbles are not uniquely identified.

However, the challenge remains of how to inspect the transfer piping and these fuel inventory locations once the facility goes hot. For the fresh fuel storage area, the radiation field should permit human access. However, this will not be the case for the reactor core, spent fuel storage bins, graphite ball storage, used fuel bin, and broken ball storage bins. Engineering design conservatism would normally dictate that the fuel handling system piping and pipe chases be accessible for maintenance and repair during plant operations, except perhaps for those portions nearest to the reactor vessel, where reactor shutdown would be required to reduce radiation levels for access. To accommodate this, the piping must also be sufficiently shielded to allow access for inspection, maintenance and repair. Inspectors must be able to confirm the integrity of the pebble fuel transfer piping and storage bin configurations, as per the original design information. These storage and piping systems are located within the reactor building to mitigate external threats. They would be more secure if the major portion of the building containing the fuel handling and storage system is embedded below grade.

The proposal for the 400 MWth PBMR building is shown in Figure 5. The current conceptual design shows only partial embedment where the spent fuel storage is below grade, but the remainder of the Fuel Handling and Storage System (FHSS) is at grade level, or above. Full embedment was studied as discussed in the references noted above, but not selected since the worst-case external threat considered was a jet airliner crash. Consequently, the designers determined it to be more cost effective to harden the reactor building above ground, than to require additional subsurface construction. While noting the strength and economics of this technical argument, additional hardening of the fresh fuel storage and transfer system that will be above grade should be considered. As has been noted, the PBMR is 
effectively a hybrid between a low-enriched uranium (LEU) fuel fabrication plant and a nuclear reactori.e., it is a modular nuclear reactor fueled by LEU, but it handles this fuel in bulk form like in a fabrication plant. While LEU fabrication plants do not necessarily have hardened bunkers for storing freshly made fuel assemblies, at the reactors these fuel assemblies are stored in secured storage wells typically collocated within the heavily secured reactor containment building. We believe that this is the level of protection and security for the fresh fuel storage and transfer system that the design team should consider. In the case of the PBMR, this could be achieved by collocating the fresh fuel storage and feed system within the reactor building, or by hardening a separate fresh fuel storage and feed building that may be above grade.

The planned start-up procedure for the PBMR has been described by Mr. Slabber of PBMR Ltd., as per the aforementioned reference. Per this procedure, the reactor uses in stages: i) all graphite moderating pebbles, ii) a mix of graphite moderating pebbles and start-up pebbles at 5.7\% U-235, and ultimately, iii) equilibrium-core pebbles at $9.6 \% \mathrm{U}-235$. The radiation detectors in the measurement verification and distribution block shown in Figure 4 must be sufficiently sensitive to characterize and sort all fuel pebbles. Ideally, based on the gross radiation attributes, irradiated graphite pebbles would be routed to the graphite storage tank, and spent fuel pebbles to the spent fuel storage tanks (bins), while recirculating core fuel pebbles to the reactor until they reach the desired optimum burn-up of $90 \mathrm{GWd} / \mathrm{t}$.

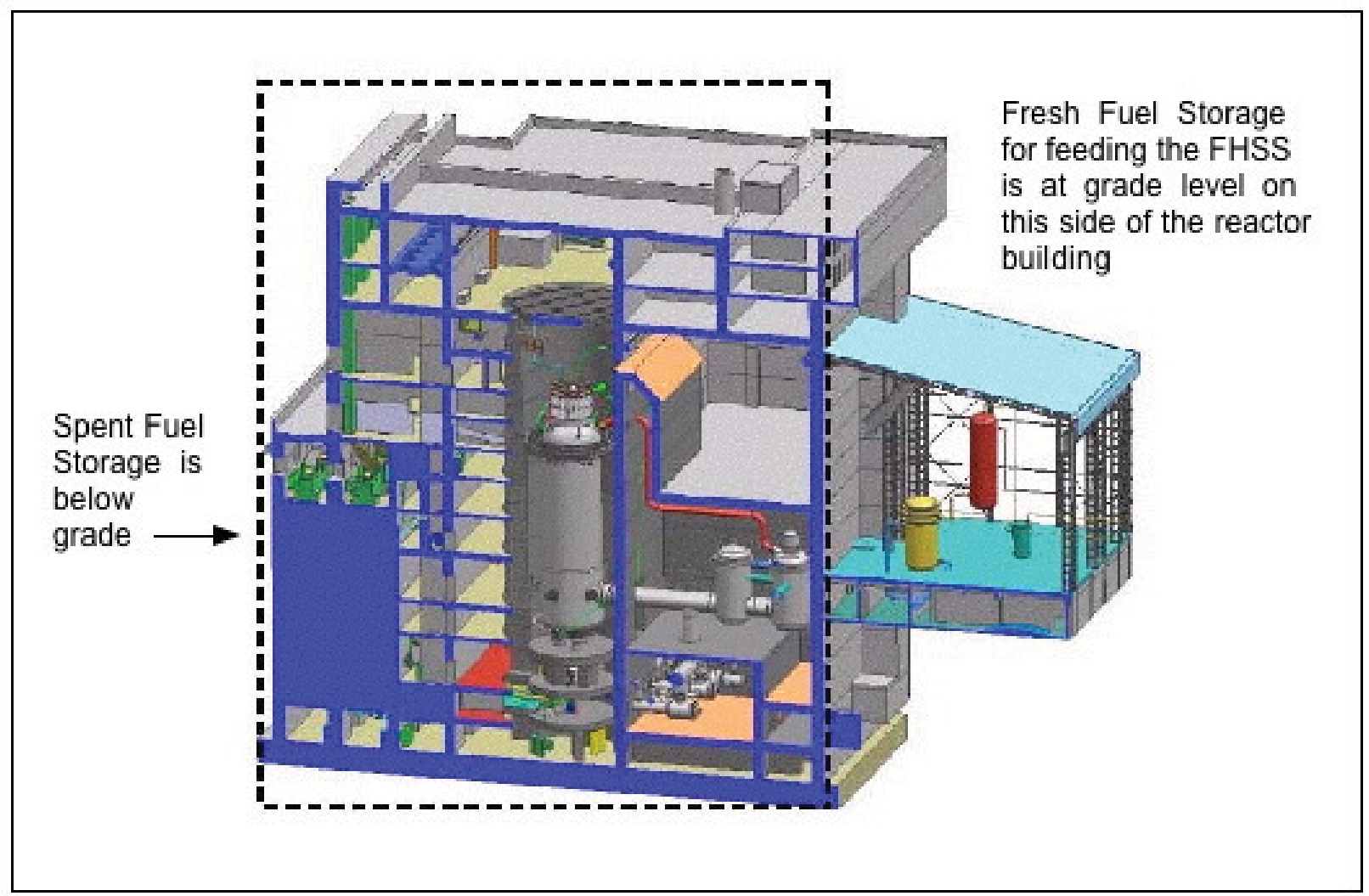

Figure 5: Cross-sectional View of PBMR Reactor Building Showing Relative Location of Fresh Fuel and Spent Fuel Storage Areas (Source - PBMR Ltd.)

Considering the importance of the measurement verification and distribution block, IAEA inspectors will need to understand the design of the system and associated gross gamma and gross neutron radiation detection system to ensure that the system will work as planned. This is important, because the IAEA will ultimately need to rely on this instrument to determine, or corroborate, the inventory of core fuel and spent fuel at the facility. Based on the current state of PBMR spent fuel verification technology, as has 
been noted, there is a need to improve the modeling, simulation, and non-destructive assay of core and spent PBMR fuel to achieve this level of discrimination. The IAEA also has an established policy regarding the joint-use of instruments for safeguards purposes with another party, such as the operator of a PBMR or the national safeguards inspectorate. ${ }^{72}$ Historically, this has made it more challenging for the operator and IAEA to use the same instrument, although one can see the mutual advantages in this case. If the instrument is shared, then the IAEA will need to ensure that the data they receive from the system has not been manipulated. Conceivably, this may entail independent data collection systems for the IAEA, as well as data encryption and authentication, and additional tamper indicating measures so that the IAEA can reach independent safeguards conclusions using the instrument. These aspects need to be considered in the design of the pebble fuel Measurement Verification and Distribution Block and associated pebble fuel radiation detectors.

The IAEA must inspect the Fuel Handling and Storage System during design information examination and verification (DIE/DIV) activities prior to start-up, to ensure that the system does not provide a means to divert fresh or irradiated fuel pebbles. Pipe chases that will become inaccessible after the facility goes hot, may require remote inspection by cameras, or other means, to verify that fuel transfer path has not been altered. Inspection access ports may be required for any pipe chase that must be otherwise sealed for safety or radiation protection. The assay systems for the Measurement Verification and Distribution Block will require verification tests of functional capability with inspector-provided dummy pebbles, which may encase various sources to simulate fresh LEU pebbles, core fuel, and spent fuel pebbles. All valves that provide access to the fuel recirculation piping must be in enclosures that can be sealed and examined for access after plant start-up. Appropriate procedures must be agreed between the IAEA and the PBMR operator for verification of safeguards relevant configuration control so that modifications are not made without the first informing the IAEA.

Mr. Slabber of PBMR Ltd. has proposed a safeguards approach shown schematically in Figure 4 that relies on fuel flow monitors, tamper indicating seals, and video surveillance systems. During the design information examination and verification activities, the IAEA inspectors will need to verify that the proposed safeguards surveillance camera locations would provide adequate coverage. The IAEA is currently developing a Next Generation Surveillance System (NGSS), as was described in general terms at the recent meeting of the United States Support Program to the IAEA in Vienna. ${ }^{73}$ Considering the tentative start-up date for the PBMR of 2018, it is likely that the IAEA will be installing the new NGSS for safeguarding new facilities. With this in mind, the designers should provide space and utilities for the NGSS cameras and modules, particularly in the locations currently identified by the IAEA and PBMR Ltd. The IAEA will also need to verify that the proposed locations for tamper-indicating seals would be effective. Electronic seals are likely to be considered, especially those capable of remotely transmitting the status of the seal, including the IAEA next generation Electro-Optical Sealing System (EOSS). In general, the IAEA is moving towards more efficient short-notice random inspections (SNRI) and remote inspections. While the PBMR Ltd. proposed safeguards approach has many merits, it is likely that the IAEA will require that many, if not all of the safeguards systems, be amenable to remote data transmission and monitoring (RM). With this in mind, the designer will need to consider the new instruments that the IAEA is using for the purposes noted and provide space and utilities for these instruments. Safeguards instruments and cameras will need uninterruptable electrical power supplies with battery back-up. For its part, the IAEA will need to demonstrate the placement and performance of these systems during the final stages of facility construction prior to hot-startup, i.e. ca. 2016 to 2018 .

As has been discussed, reliance on an item accounting safeguards approach is not feasible, because of the large number of indistinguishable small fuel elements. For this reason, we recommend a hybridized safeguards approach that would also use bulk nuclear material verification measures. Since each fresh fuel pebble contains only 9 grams of low enriched uranium in a spherical fuel pebble having a mass of 200 grams, keeping track of thousands of pebbles appears at first blush to be impractical; however, when the special nuclear material (SNM) content of the fresh and irradiated pebble is examined, the mass and 
volume of material that must be diverted become evident and the problem of diversion becomes one of being able to hide the diversion of metric tons and cubic meters of graphite. The SNM content of irradiated pebbles has been calculated by the designer and several other independent analysts and is consistent with the estimates shown in Table $5 .^{74}$ The abrupt diversion of 1 SQ of LEU in the form of fresh fuel would require a container, or multiple containers, having a total volume between of $20-25 \mathrm{~m}^{3}$. This is equivalent to between five and six standard-sized dump trucks in the United States - a very large movement of bulk material and one that should be detectable with effective safeguards measures. For the diversion of one SQ plutonium in the form of spent fuel, the diverter would require two to four standard sized dump trucks. Additionally, the spent fuel would need to be packed in shipping casks, because of the high radiation, which would make the material movement bulkier and easier to detect. By comparison with a typical light water reactor, a single fresh PWR fuel assembly contains an average of 1/4 SQ of LEU. A fully irradiated PWR fuel subassembly (at $55 \mathrm{GWd} / \mathrm{t}$ ) contains $1 / 2 \mathrm{SQ}$ of plutonium. In all cases for the PWR the nuclear material content of a given volume of PWR vs. PBMR fuel is ten times greater, or more.

Analysts have examined the potential of using specially designed target pebbles for clandestine plutonium production in the PBMR. ${ }^{75,76,77}$ The conclusions reached from these studies are: i) One would need at least a few tens of thousands of pebbles of a special design to produce 1 SQ of plutonium of weapons-grade plutonium on a single pass irradiation, ii) The specially designed pebbles would be more likely to leak fission products than the standard fuel element, and iii) The reactivity balance of the core would be upset by the use of such pebbles. A reactivity imbalance would be indicated by a control rod positioning abnormality. Generally, all the control rods will be nearly fully withdrawn to match the positive core reactivity from the on-line refueling of fresh and recirculation of partially irradiated core fuel. Consequently, a means exists to monitor for the introduction of specially designed pebbles for undeclared target irradiation to produce weapons grade plutonium. A concurrent study being performed at ORNL, relevant to this discussion, proposes the use of the following safeguards measures to detect undeclared target irradiation or diversion of nuclear material from a PBMR: ${ }^{78}$

- Pebble Radiation Inspections during Pebble Recirculation: The pebbles flow through the reactor during irradiation and then upon discharge from the reactor though a detector to determine which pebbles are sufficiently irradiated for disposal, and which pebbles are to be recirculated. The radiation profile of a "special target pebble" would be different from a fuel pebble, and thus could be detected, in principle. It is also likely that a "special target pebble" would have a higher loading of natural or depleted uranium than a normal fuel pebble. This, in turn, means a heavier pebble. As a practical matter for potential proliferators, pebble inspection is how the host country would find the special target pebbles sorted from the rest of the fuel. There are strong incentives to use the reactor's pebble inspection system as an integral component of the safeguards tracking system.

- Monitoring of Fuel Recirculation Records: The use of a large number of special target pebbles would result in power and reactivity shortfalls in the reactor. That is, the fresh fuel loading or enrichment or the enrichment of spent fuel would need to increase to provide the neutrons for the target pebbles. Significant discrepancies between fuel loadings and power output would be strong indicators of misuse of the reactor for undeclared target irradiation. In this context, the PBMR has a unique feature - all of the spent fuel has approximately the same burn-up. This characteristic makes it potentially easier to compare power production records with fuel usage to determine potential discrepancies.

Designers of the PBMR and the IAEA should also consider the possible use of these tools for enhancing the safeguarding of the PBMR.

Regarding bulk material verification, the most important design consideration is to provide the ability to inspect the spent fuel storage tanks to ensure that large amounts of spent fuel (dump truck loads) have not been diverted. The use of gamma detectors, to detect fission products (by burn-up correlation), and 
fission chambers, to detect subcritical neutron multiplication from the occurrence of spontaneous fission in $\mathrm{Pu}-240$, should be demonstrated and qualified. Active interrogation on one side of the spent fuel storage tank by inserting a neutron source, while gamma and neutron detectors are inserted along the opposite side of the spent fuel tank, could potentially provide another more direct method for verifying the plutonium inventory as function of height. The storage tanks would need to be pre-mapped before neutron interrogation could be used, to reduce statistical uncertainties and to give dual indication of the fissile content and distribution in the storage tank. This would require multiple monitoring penetrations and tubes down the sides of storage tanks, with one of sufficient size to accommodate a small neutron generator. Use of the Nuclear Materials Identification System (NMIS) in active interrogation mode, with statistical correlations to account for the radiation noise from surrounding storage tanks, may allow the estimation of the fissile content (U-235, Pu-239) in the storage tanks to within less than a few percent of mass.

Independent safeguards experts and analysts have also considered the technical difficulty of reprocessing fully burned PBMR fuel and have determined that the physical form, high burn-up, and low nuclear material content does not warrant release or exemption from safeguards, which will be discussed in more detail in the following section. ${ }^{79}$

\subsection{Other Relevant Issues}

\subsubsection{Spent PBMR Fuel - Can it be Reprocessed?}

The issue whether spent PBMR fuel can be effectively reprocessed to recover the plutonium, especially in terms of safeguards, is part of the broader question: Does the fuel meet the IAEA criteria for termination of safeguards on measured discards? That is, after the IAEA has adequately verified the flow of the spent fuel to the spent fuel bins, can the IAEA terminate safeguards on this material? The short answer is no.

A more detailed response is excerpted below from the summary of a study performed by Ougouag, Gougar, and Todd of INL in 2006, as requested by the IAEA through the U.S. Support Program, entitled, "Evaluation of the Strategic Value of Fully Burnt PBMR Spent Fuel:" 80

The spent fuel from the PBMR-400 reactor has been evaluated for suitability for further utilization in nuclear applications. The approach taken in this evaluation is detailed and justified and the conclusions of this study are presented.

The PBMR-400 is considered against criteria derived from the INFCIRC/66, INFCIRC/153 (corrected), and the IAEA Safeguards Manual. The principal conclusion of this study is that per the criteria of INFCIRC/66, INFCIRC/153 (corrected), and the IAEA Safeguards Manual, the fully burnt spent fuel from the operation of the South African PBMR-400 pebble bed reactor must remain under safeguards until such time as it is (chemically) treated to separate the fissile material from it. The spent fuel does not meet the criteria for termination of safeguards on measured discards. However, the PBMR spent fuel will not require safeguards more stringent than those that apply to spent fuel from current generation of light water reactors or to the spent fuel of other high temperature gas-cooled reactors currently being considered for development by some entities worldwide. [Emphasis added] 
For all cases, the Pu-238 content is very far from the $80 \%$ content required for termination of safeguards on measured discards. The fissile isotopes content per pebble (especially Pu-239) are small but sufficiently large to be attractive to a would-be proliferator. The fissile isotopes contents of the spent fuel, predicted through modeling, are roughly the same magnitude as the fissile content of fresh light water reactor fuel. As a consequence, with a small amount of processing the PBMR-400 spent fuel could be used as a source of fuel for another reactor, albeit not another PBMR. For proper perspective, it must be noted that the residual fissile isotopes content of prismatic block HTR concepts is slightly higher than that of spent PBMR-400 fuel, implying at least similar safeguards constraints.

The reprocessing of TRISO-based spent fuel is a difficult and expensive undertaking. Notwithstanding the expense, the fissile content of TRISO-based spent fuel cannot be viewed as irrevocably irretrievable from the point of view of safeguards.

The conclusion of this study is that the fully burnt spent fuel from the PBMR-400 reactor does not meet the IAEA criteria for termination of safeguards on measured discards. Therefore, safeguards should be maintained on such spent fuel until it has been treated to meet said IAEA criteria. For completeness, it is important to note that the spent fuel from prismatic block HTRs would have to be subjected to at least the same restrictions.

The TRISO fuel kernels, with their impenetrable silicon carbide and pyrolytic carbon and graphite coatings insure high integrity of the PBMR fuel pebbles for retaining fission product gases and, hence, render further chemical processing difficult. However, reprocessing of HTGR fuel had at least been demonstrated on a pilot-scale at the ICPP in the 1980s with the demonstration of the Rover Reprocessing Head-end. ${ }^{81,82}$ This process was demonstrated for the HTGR Rover rocket fuel at the ICPP, a small reprocessing plant that reprocessed spent fuel from the U.S. Navy's nuclear powered ships. The process used a crusher and pyrolytic burner to crush and burn the silicon carbide and pyrolytic graphite coatings. There were several burners in series to ensure complete combustion of the graphite and carbide coatings. After combustion, the uranium-bearing ash was separated from the alumina bed material that carried over from the fluidized combustors by cyclone separators. The uranium bearing ash was subsequently dissolved in a mixture of nitric-acid, hydrofluoric acid and aluminum nitrate. Solids were removed from the spent fuel dissolver solution, which was then fed to geometrically-safe small mixer-settlers for solvent extraction and co-decontamination from the fission-products. The fission product bearing solution was routed to high level active waste (HLW), while the Rover spent fuel dissolver solution was fed to a centrifuge to remove any insoluble solids, including silica and ruthenium compounds. This solution was then transferred to a pre-feed adjustment tank, where the solution was adjusted to meet the feed specification for the first extraction cycle of the reprocessing plant.

Similarly, regarding the head-end reprocessing of HTGR fuel, the reference notes: ${ }^{83}$

Attempts in the 1960s to avoid burning the (prismatic) graphite blocks were not successful. Even when the blocks were ground to 200 mesh, the fuel was not completely leached from the graphite. And hydrocarbon reaction products of the carbides with nitric acid caused poor phase separation in later solvent extraction. Thus all HTGR reprocessing systems now plan to convert fuel to UO2 and ThO2 before dissolution.

Despite the technical difficulties of reprocessing HTGR fuel, it had been demonstrated on a pilotengineering scale and remains technically feasible, although there has not yet been a compelling economic demand to demonstrate it on a large commercial scale.

\subsubsection{Is Plutonium in Spent PBMR Fuel Weapons Usable?}

Slabber of PBMR (Pty) Ltd. asserts that the PBMR is not suited for the production of weapons-grade plutonium (i.e. $\mathrm{Pu}-239>90 \%$ ) and that this factor should be considered in the design of the safeguards measures required for the core and spent fuel. ${ }^{84}$ Additionally, he notes: 
In a pebble fuel reactor, attempts to divert nuclear material will be detected promptly. Any attempt to clandestinely introduce target material for the production of weapons material will also be detected and displayed in the operational records. It is impossible to produce weapons grade plutonium in a target of $U-238$, because in a single pass, the Pu-240 isotope is larger than 20\% of the Pu-239.

While this is a rational argument, the IAEA considers all plutonium isotopes as plutonium, and hence safeguardable, excepting the case of $\mathrm{Pu}-238$ thermoelectric sources where the $\mathrm{Pu}-238$ content exceeds $80 \%$. Otherwise, the isotopic content of the plutonium is irrelevant in terms of international safeguards, and the accounting for such material is on an elemental $(\mathrm{Pu})$ basis.

Also relevant to this discussion, recent U.S. DOE National Laboratory studies under the SPIKE Project funded by NA-243, state the following: ${ }^{85,86}$

This is an extension of earlier studies that examined the attractiveness of materials mixtures containing special nuclear materials (SNM) and alternate nuclear materials (ANM) associated with the PUREX, UREX, COEX, THOREX, and PYROX reprocessing schemes...The primary conclusion of this study is that all fissile material needs to be rigorously safeguarded to detect diversion by a state and provided the highest levels of physical protection to prevent theft by sub-national groups; no "silver bullet" has been found that will permit the relaxation of current international safeguards or national physical security protection levels.

Whether the plutonium is "reactor-grade" or "weapons-grade" has been argued since the initial application of international safeguards. The IAEA and its Board of Governors ultimately agreed that all plutonium-bearing material, with the exception noted above for $\mathrm{Pu}-238$, will be accounted and safeguarded similarly.

\subsubsection{Anti-Neutrino Detectors as a Safeguards Tool for the Future}

Anti-neutrino detectors have been proposed to enhance the safeguarding of research reactors and nuclear power plants by the IAEA, including the PBMR. Researchers have demonstrated that anti neutrino particle detectors buried beneath a nuclear reactor would record and indicate whether the reactor was operating. Proper evaluation of this data could even indicate the relative reactor power output, hence, plutonium production in the reactor. ${ }^{87}$ This being said, this safeguards measure is in a very early stage of development, and it is not entirely clear what the added benefit would be, in connection with the established safeguards approach for nuclear power plants in general, and the PBMR specifically. The prospective safeguards approach appears straightforward and similar to the application of safeguards at an On-Load Refueled Reactor (OLR, CANDU-type), provided continuity of knowledge is maintained over the core fuel and spent fuel. At this stage, the containment/surveillance system configuration proposed by Slabber, et al., of PBMR (Pty.) Ltd., with the proposed hybridized safeguards approach for bulk nuclear material verification, would be consistent with IAEA practice for safeguarding comparable nuclear materials and facilities. With this equipment in place under current the safeguards criteria, the IAEA would conduct an annual PIV, together with periodic re-verification of the facility and updated design information. If the installed safeguards equipment is set up in an unattended remote-monitoring (RM) mode, as is envisioned, inspectors should be able to conduct infrequent short-notice random inspections (SNRI) to confirm that the safeguards systems are operational and that the reactor remains properly safeguarded. With this in mind, it is difficult to imagine the safeguards benefits that would justify the cost of procuring and installing anti-neutrino detectors beneath more than 440 nuclear power plants and hundreds of research reactors operating worldwide. In any event, the IAEA is considering the use of antineutrino detectors in selected cases, with the PBMR as one of those cases. More cannot be said in this regard until additional data concerning the cost and safeguards benefit of this safeguards measure are better known. This is an area for further analysis, once the design of the PBMR becomes better known and the specific safeguards approach can be optimized. 


\subsubsection{Aspects of the Long-term Storage of Spent PBMR Fuel}

Interestingly, the high integrity design of TRISO fuel kernels, with their impenetrable silicon carbide and pyrolytic graphite and carbon coatings, may make the long term storage of PBMR spent nuclear fuel easier. According to the reference cited, regarding spent fuel assemblies: ${ }^{88}$

Scoping calculations suggest HTGR spent fuel is a superior waste form to LWR spent fuel. This should simplify licensing and may reduce cost per unit volume for the waste package.

The PBMR fuel spheres (TRISO) provide a multi-barrier for containment, given that the stable silicon carbide layer around the uranium will last for more than a million years and the coal-like graphite itself does not degrade underground or within running water.

Recently, at the Meeting of the United States Support Program to the IAEA in Vienna, Austria, Mr. Bruce Moran of the Safeguards Division of Concepts and Planning outlined a futuristic safeguards approach for the long-term safeguarding of spent fuel repositories. ${ }^{89}$ This approach was comprehensive and relied upon elaborate verification of the repository design and construction, and the use of redundant and complementary containment/surveillance measures. It is also supported by other geophysical tools to ensure that spent fuel is not removed from an entombed repository. The safeguards measures noted appear to be relevant to the safeguarding of PBMR spent fuel pebbles long-term as well. Consequently, PBMR spent fuel pebbles should be no more challenging to safeguard long-term than spent fuel from LWRs, research reactors, or other on-load refueled reactors, such as CANDU. The monitoring of the spent fuel pebble storage bins would be comparable to the monitoring of away-from-reactor (AFR) LWR spent fuel assembly storage silos and casks. Relevant to the earlier discussion about re-verifying the PBMR reactor core, work is currently on-going regarding the re-verification of spent fuel in AFR storage if C/S is lost in that case as well. This problem is not unique to PBMR, but remains a current safeguards challenge for many nuclear facilities and storage locations - including spent fuel repositories. While we do not mean to give this topic scant attention, we simply note that this is a need that PBMRs and all reactors would have in common - effective safeguards for the interim-term or long-term spent fuel repository. We also assert that this could be effectively addressed with the complementary and redundant safeguards measures as proposed by the IAEA. However, this safeguards approach should be demonstrated on at least interim spent fuel storage facilities, before they are applied to long-term spent fuel repositories. 


\section{CONCLUSIONS AND RECOMMENDATIONS TO NNSA}

Despite the fact that the PBMR design is still in flux, the National Laboratory PBMR Safeguards Team studied the proposed nuclear safeguards for this reactor and drew significant conclusions regarding the Pebble Bed Modular Reactor type, consistent with the IAEA's earlier technical assessment.

These conclusions are:

1. The IAEA Safeguards Criteria does not fit the Pebble Bed Modular Reactor, under the categories of light water reactor (LWR), on-load refueled reactor (OLR, i.e. CANDU), or "Other." Because the nuclear fuel is dispersed across such a large bulk of material, it could be classified as a "bulk-fuel reactor," and unique safeguards criteria should be developed for this reactor type by the IAEA, in cooperation with affected IAEA Member States, and international safeguards partners, such as U.S. DOE and NNSA.

2. In developing the new safeguards criteria, the IAEA should consider the bulk nature of the fuel. The traditional requirement to identify discrete fuel assemblies in the LWR, OLR or Other-type reactors, and verify those randomly for uranium, U-235, plutonium, and/or thorium content, does not seem feasible or relevant in the case of the PBMR. Verification of the fresh, core and spent fuel are more akin to U-235 or plutonium verification in a uranium or MOX fuel fabrication plant. DOE/NNSA should work with the IAEA to make certain that this aspect is practically addressed, and that undue emphasis is not placed on the identification and verification of individual fuel pebbles.

3. The ideal safeguards approach appears to be a hybridized approach employing fuel flow monitoring, redundant advanced containment and surveillance, and bulk nuclear material accountancy and verification techniques. This layered approach would provide safeguards "defense in depth" that the item facility and bulk facility approach cannot provide alone.

4. The IAEA originally considered whether nuclear material in spent PBMR fuel was irrecoverable because of the highly refractory nature of the fuel. However, reprocessing of similar HTGR fuel has been demonstrated in the United States at the Idaho Chemical Processing Plant (ICPP). Consequently, the recovery of plutonium and uranium from PBMR spent fuel must be considered possible, although technically challenging. This has been confirmed by a separate Idaho National Laboratory (INL) report on the subject.

5. Close cooperation between PBMR (Pty) Ltd., the IAEA, DOE/NNSA, and the DOE National Laboratories to develop a safeguards approach, is essential to address the unique nature of the PBMR (i.e., continuous on-load refueling with nuclear fuel in bulk form).

Based on the conclusions noted, the National Laboratory PBMR Safeguards Team recommends the following next steps to NNSA, in relative order of priority:

Near-term (6 Months to 1 Year)

1. Recommend to the IAEA Department of Safeguards, Operations Division SGOB and the Division of Concepts and Planning (SGCP), the development of new safeguards criteria better suited to safeguarding the PBMR and other bulk-fuel reactors. This recommendation has previously been supported by the IAEA when the development of the PBMR was first made public.

2. Support the National Laboratory PBMR Safeguards Team to re-evaluate the safeguards considerations and optimum safeguards approach for the reactor, once the redesign of the reactor has been finalized.

3. Request a detailed briefing from the reactor developer, PBMR (Pty.) Ltd., to review the recent design changes so that NNSA can help support PBMR safeguards by focusing research and 
development in support of safeguards tools and equipment amenable to improving the safeguarding of this and related bulk-fuel reactors likely to be marketed.

4. Raise the PBMR safeguards issues and concerns noted to PBMR (Pty.) Ltd. so reactor designers can make provisions for the proposed safeguards systems including: the IAEA Next Generation Surveillance System (NGSS), EOSS next generation sealing system, and custom designed fuel flow monitors. The facility design should also accommodate the tracing and verification of the extensive fuel transfer system during the IAEA design information examination and verification activity (DIE/DIV). The designer should consider how the extensive fuel transfer paths would be re-verified by the IAEA, once the facility goes hot and operational. The redesign of the reactor allows a window for more detailed and timely nuclear safeguards input in keeping with the concept of Safeguards-byDesign.

Mid-term (1 to 3 Years)

1. Continue to support development and optimization of: i) techniques to verify the plutonium content or radiation attributes of spent fuel pebbles, ii) burn-up computer codes for PBMR spent fuel, and iii) bulk verification techniques for PBMR spent fuel storage bins. The need to re-verify the spent fuel storage bins at some point in the future is likely, and the IAEA will need the tools to perform this task - which they do not presently have. More accurate non-destructive assay techniques for verifying the recirculating PBMR core and spent fuel could ultimately lead to a continuous on-line assay system that could be used jointly by the inspector for safeguards purposes and plant operator for monitoring fuel burn-up and reactor performance. The first two issues are currently being supported by NA 24, but the third item has not previously been defined as a need.

2. Continue to support development of the IAEA Next Generation Surveillance System (NGSS), which would greatly aid the implementation of safeguards at the PBMR and other nuclear facilities under IAEA safeguards.

3. Continue to support the development and vulnerability testing of the next generation IAEA Electro-Optical Sealing System (EOSS), which would greatly aid the implementation of safeguards at the PBMR and other nuclear facilities under IAEA safeguards.

4. Support the development of effective fuel flow monitors for the PBMR. The optimized design of the flow monitors will depend on the results of the PBMR spent fuel characterization and modeling studies currently in progress. For the PBMR safeguards approach to be effective, the flow monitors need to be able to reliably discriminate between irradiated graphite moderator spheres, fresh fuel, low burn-up fuel, and high burn-up spent fuel. This has yet to be practically demonstrated.

Long-term (3 to 5 years)

4. Recommend that the IAEA begin field design information examination and verification (DIE/DIV) of the reactor as soon as construction begins, tentatively scheduled for 2014.

5. During the DIE/DIV, recommend that the IAEA pay particular attention to the verification and testing of the numerous fuel flow monitors and the need for bulk volume measurement systems, especially for the spent fuel bins, used fuel bin, graphite ball storage bin, damaged fuel bins, etc.

6. Support the IAEA in developing an effective safeguards approach for the PBMR, which needs to be implemented prior to the 2018 start-up of the demonstration reactor in Koeberg, South Africa. 
(This page left intentionally blank) 


\section{REFERENCES}

${ }^{1}$ Shropshire, D.E., and Herring, J. S. (INL): "Fuel Cycle and Nuclear Material Disposition Issues Associated with High-Temperature Gas Reactors," Proceedings of the ANES, Miami Beach, FL, October 3-6, 2004.

${ }^{2}$ Hertzler, T. (SAIC): "Technical and Regulatory Review of the Rover Nuclear Fuel Process for Use on Fort St. Vrain Fuel," Science Applications International Corporation (SAIC), for EG\&G Idaho Inc., Report \# EGG-WTD-10550, Idaho Falls, ID, February, 1993.

${ }^{3}$ Stacy, S, and Braun, J. (INL): "Historic American Engineering Record - Idaho National Laboratory, Idaho Chemical Processing Plant, Fuel Processing Complex," U.S. DOE Idaho National Laboratory (INL), Report \# INL/EXT-06-11969, Idaho Falls, ID, December, 2006.

${ }^{4}$ Benedict, M., Pigford, T. H., and Levi, H. W.: "Nuclear Chemical Engineering," McGraw Hill Chemical Engineering Series, Second Edition, New York, 1981, pp-147-149, and 514-526.

${ }^{5}$ Daniels, F.: "Suggestions for a High Temperature Pebble Pile," Report \# N-1668b or MUC-FD-8, University of Chicago, Metallurgical Laboratory, Chicago, IL, October 25, 1944 (declassified January 11, 1956).

${ }^{6}$ U.S. Government Patent Office: Patent US 2809931, "Neutronic Reactor System," October 15, 1957.

${ }^{7}$ U.S. Government Patent Office: Patent US 2910416, "Neutronic Reactor," October 27, 1959.

${ }^{8}$ Amorosi, A. (ORNL): "Gas Cooled Pebble Piles," Report \# M-4079, Clinton Laboratories, Oak Ridge, TN, August 7, 1947 (declassified December 5, 1955).

${ }^{9}$ Sanderson and Porter Architect-Engineers: "Design and Feasibility Study of a Pebble Bed Reactor Steam Power Plant," Report \# NYO-8753, Vols. I and II (Del.), (originally issued as Report \# S and P 1963, Vols. I and II), Sanderson and Porter, New York, May 1, 1958.

${ }^{10}$ Oak Ridge National Laboratory: "Review of S and P 1963, the Pebble Bed Reactor," Central Files Report \# ORNL/CF-58-7-65, U.S. DOE Oak Ridge National Laboratory, Oak Ridge, TN, 1958.

${ }^{11}$ Oak Ridge National Laboratory: "Conceptual Design of the Pebble Bed Reactor Experiment," Report \# ORNL/TM-201, Oak Ridge National Laboratory, Oak Ridge, TN, 1962.

${ }^{12}$ Patent Office of the United Kingdom of Great Britain and Northern Ireland: UK Patent No. GB 834978, "Nuclear Reactor with Gas Cooling," May 18, 1960.

${ }^{13}$ Patent Office of the Republic of France: French Patent No. FR 1265484, "Nuclear Reactor whereby the Fuel in the Shape of Balls or the Like is Poured into the Reactor Core," May 23, 1961

${ }^{14}$ Flak, A: "S. Africa Sees First Pebble Nuclear Reactor by 2018," Reuters News Agency, Johannesburg, South Africa, June 23, 2009.

${ }^{15}$ Holman, J.: "PBMR Modifies the Design for the Koeberg Demo Power Plant," Engineering News, Johannesburg, South Africa, August 7, 2009.

${ }^{16}$ U.S. Department of Energy, National Nuclear Security Administration: "Next Generation Safeguards Initiative," Office of Non-Proliferation and International Security (NA 24), Washington, D.C., November, 2008, page-16. 
${ }^{17}$ International Atomic Energy Agency: "Pebble Bed Modular Reactors (PBMR) - Safeguards Approach and Equipment Requirements," Presentation by G. Horton on the occasion of the Meeting of the United States Support Program to the IAEA in Vienna, Austria, May 20, 2009.

${ }^{18}$ Flak, A: "S. Africa Sees First Pebble Nuclear Reactor by 2018," Reuters News Agency, Johannesburg, South Africa, June 23, 2009.

${ }^{19}$ Slabber, J.: "Pebble Fuel Advantages," Proceedings of the $2^{\text {nd }}$ International Topical Meeting on High Temperature Reactor Technology, Beijing, China, September 22-24, 2004.

${ }^{20}$ Slabber, J.: "PBMR Nuclear Material Safeguards," Proceedings of the $2^{\text {nd }}$ International Topical Meeting on High Temperature Reactor Technology, Beijing, China, September 22-24, 2004.

${ }^{21}$ International Atomic Energy Agency: IAEA Safeguards Glossary - 2001 Edition, International Nuclear Verification Series No. 3, Vienna, Austria, 2002, page-23.

${ }^{22}$ Matzie, R., and Greyvenstein, G.: "Pebble Bed Modular Reactor Project Status," International Conference of Advanced Power Production (ICAPP), Presentation by Westinghouse Electric Co. and PBMR (Pty) Ltd., May 27, 2009

${ }^{23}$ International Atomic Energy Agency, Department of Safeguards: Safeguards Manual-Parts SMI and SMC, Safeguards Criteria, Sections SMC-1, 2 and 3, Vienna, Austria, 2004.

${ }^{24}$ International Atomic Energy Agency: Safeguards Manual - Parts SMI and SMC, SMC-3, Safeguards Criteria, "Other Types of Reactors," Vienna, Austria, 2004.

${ }^{25}$ International Atomic Energy Agency: IAEA Safeguards Glossary - 2001 Edition, International Nuclear Verification Series No. 3, “Table-II: Significant Quantities,” Vienna, Austria, 2002, page-23.

${ }^{26}$ International Atomic Energy Agency: The Structure and Content of Agreements Between the Agency and States Required in Connection with the Treaty on the Non-proliferation of Nuclear Weapons, IAEA INFCIRC/153 (corrected), paragraph 28, Vienna, June, 1972.

${ }^{27}$ International Atomic Energy Agency: The Agency's Safeguards System (1965, as Provisionally Extended in 1966 and 1968), IAEA INFCIRC/66 (Revision-2), Vienna, Austria, September 1968.

${ }^{28}$ Goldschmidt, P.: "Concrete Steps to Improve the Nonproliferation Regime," Nonproliferation Program, Number 100, Carnegie Endowment for International Peace, April, 2009.

${ }^{29}$ Ougouag, A.M., Gougar, H. D. and Todd, T. A.: "Evaluation of the Strategic Value of Fully Burnt PBMR Spent Fuel,” U.S. DOE Idaho National Laboratory, Report \# INL/EXT-06-11272, Idaho Falls, ID, May, 2006.

${ }^{30}$ Hening, J.S., Lebenhaft, J.R., Weaver, K.D., and Driscoll, M.J.: "Plutonium Production in a Pebble Bed Reactor," personal communication, Los Alamos National Laboratory, Los Alamos, NM, 2000.

${ }^{31}$ Beddingfield, D.H., and Hori, M.: "Nuclear Safeguards Challenges at Reactors Types that Defy Traditional Item Counting," JAEA-IAEA Workshop on Advanced Safeguards Technology for the Future Nuclear Fuel Cycle, Tokaimura, Japan, 13-16 November, 2007.

${ }^{32}$ Slabber, J.: "PBMR Nuclear Material Safeguards," Proceedings of the 2nd International Topical Meeting on High Temperature Reactor Technology, Beijing, China, Sept. 22-24, 2004. 
${ }^{33}$ Ougouag, A.M., Gougar, H. D., and Todd, T.A.: "Evaluation of the Strategic Value of Fully Burnt PBMR Spent Fuel," U.S. DOE Idaho National Laboratory, Report \# INL/EXT-06-11272, Idaho Falls, ID, May, 2006, pg. 11.

${ }^{34}$ Greneche, D. and Brossard, P.: "The Reprocessing Issue for HTR Spent fuels," Proceedings of ICAPP '04, Pittsburgh, June 13-17, 2004, pp. 435-444.

${ }^{35}$ International Atomic Energy Agency: Safeguards Manual - Parts SMI and SMC, SMC-14, Annex 6, "Procedures for Sampling Plans," Vienna, Austria, 2004. (Internal IAEA Document)

${ }^{36}$ International Atomic Energy Agency, Department of Safeguards: "New Safeguards Equipment Systems - Teaming IAEA Inspectors with Technology,” Vienna, Austria, 2002.

${ }^{37}$ Slabber, J.: "PBMR Nuclear Material Safeguards," Proc. 2nd Int'l Topical Meeting on High Temperature Reactor Technology, Beijing, China, Sept. 22-24, 2004.

${ }^{38}$ International Atomic Energy Agency: Safeguards Glossary - 2001 Edition, Vienna, Austria, 2002, pg. 68.

${ }^{39}$ Pellaud, B.: "Proliferation Aspects of Plutonium Recycling," Journal of Nuclear Materials Management, Fall 2002, Volume XXXI, No. 1, pg. 31.

${ }^{40}$ Beddingfield, D.H., and Hori, M.: "Nuclear Safeguards at Reactor Types that Defy Traditional Item Counting," Proceedings of the JAEA-IAEA Workshop on Advanced Safeguards Technology for the Future Nuclear Fuel Cycle, Tokaimura, Ibaraki-ken, Japan, Nov 13-16, 2007 - (also Los Alamos National Laboratory Report, LA-UR-07-6878, 2007).

${ }^{41}$ Goldschmidt, P.: "Concrete Steps to Improve the Nonproliferation Regime," Nonproliferation Program, Number-100, Carnegie Endowment for International Peace, April, 2009.

${ }^{42}$ International Atomic Energy Agency: Safeguards Manual - Parts SMI and SMC, SMC-3, Safeguards Criteria, "Other Types of Reactors," Vienna, Austria, 2004. (Internal IAEA Document)

${ }^{43}$ Teuchert, E, et al.: "VSOP94: Very Superior Old Programs - Computer Code System for Reactor Physics and Fuel Cycle Simulation - Input Manual and Comments," Jülich Research Centre, Jülich, Federal Republic of Germany, 1994.

${ }^{44}$ Stoker, C.C., Reitsma, F., and Karriem, Z.: "Creation of the Equilibrium Core Origen-S Cross Section Library," Proc. HTR-2002 Conference on High-Temperature Reactors, Petten, Netherlands, April 22-24, 2002.

${ }^{45}$ Terry, W.K., Gougar, H.D., Ougouag, A.M.: "Direct Deterministic Method for Neutronics Analysis and Computation of an Asymptotic Burnup Distribution in a Recirculating Pebble-Bed Reactor," Ann. Nucl. En., 29, 11 (2002) 1345-1364.

${ }^{46}$ Rutten, H.J.: “The Depletion Computer Code ORIGEN-JUEL-II,” Forschungszentrum Jülich, 1993.

${ }^{47}$ Gauld, I, and Lee, S.Y: "Progress Report on PBMR Library Development," personal communication, May, 2009.

${ }^{48}$ Ilas, G., Gauld, I. and Lee, S. Y. (ORNL): "Development of ORIGEN Libraries for HTR-10 Spent Fuel Safeguards Analyses - Interim Status Report," U.S. DOE Oak Ridge National Laboratory Report \# ORNL/TM-2009/164, June, 2009.

${ }^{49}$ PBMR Ltd.: "Project Update - PBMR Ltd. Annual Report," Pebble Bed Modular Reactor Limited, Johannesburg, South Africa, 2008. 
${ }^{50}$ Tobin, S. J., Demuth, S. F., Fensin, M. L., Hendricks, J.S., Menlove, H. O., and Swinhoe, M. T.: "Determination of Plutonium Content in Spent Fuel with NDA - Why an Integrated Approach," Annual Meeting of the Institute of Nuclear Material Management (INMM), Nashville, TN, 2008.

${ }^{51}$ Rudy, C. R., et al.: "Determination of Plutonium in Spent Nuclear Fuel Assemblies by X-Ray Fluorescence," Proc. 46 ${ }^{\text {th }}$ Ann. INMM, Phoenix, Arizona, July 10-14, 2005 - (also Los Alamos National Laboratory Report, LA-UR-05-4843, 2005).

${ }^{52}$ Beddingfield, D.H., and Menlove, H.O.: "Passive Neutron Reactivity Measurement Technique," U.S. DOE Los Alamos National Laboratory Report, LA-UR-99-878, Los Alamos, New Mexico, 1999.

${ }^{53}$ Tobin, S.J., S. F. Demuth, M. L. Fensin, J. S. Hendricks, H. O. Menlove, and M. T. Swinhoe: "Determination of Plutonium Content in Spent Fuel with NDA Why an Integrated Approach," Annual Meeting of the Institute of Nuclear Material Management (INMM), Nashville, TN, 2008.

${ }^{54}$ International Atomic Energy Agency: Safeguards Manual - Parts SMI and SMC, SMC-3, Safeguards Criteria, "Other types of Reactors," Vienna, Austria, 2004. (Internal IAEA Document)

${ }^{55}$ International Atomic Energy Agency: "Pebble Bed Modular Reactors (PBMR) - Safeguards Approach and Equipment Requirements," Presentation by G. Horton on the occasion of the Meeting of the United States Support Program to the IAEA in Vienna, Austria, May 20, 2009.

${ }^{56}$ Bueker, H.: “A Safeguards-System for Pebble Bed Reactors," Journal of Nuclear Materials Management, 1976, pp. 391-399.

${ }^{57}$ Slabber, J.: "PBMR Nuclear Material Safeguards," Proc. 2nd Int'l Topical Meeting on High Temperature Reactor Technology, Beijing, China, Sept. 22-24, 2004.

${ }^{58}$ Bueker, H.: “A Safeguards-System for Pebble Bed Reactors," Journal of Nuclear Materials Management, 1976, pp. 391-399.

${ }^{59}$ Beddingfield, D.H.: Personal Communication with Chinese operators of the HT-10 Reactor in Tsinghua, China, regarding pebble fuel count in reactor core, May, 2009.

${ }^{60}$ Beddingfield, D.H., and Hori, M.: "Nuclear Safeguards at Reactor Types that Defy Traditional Item Counting," Proceedings, JAEA-IAEA Workshop on Advanced Safeguards Technology for the Future Nuclear Fuel Cycle, Tokaimura, Ibaraki-ken, Japan, Nov 13-16, 2007 - (also Los Alamos National Laboratory Report, LA-UR-07-6878, 2007).

${ }^{61}$ Metcalf, R., et al.: "Report of the Workshop on Nuclear Facility Design Information Examination and Verification (DIE/DIV) for Safeguards," U.S. DOE Idaho National Laboratory (INL) Report \# INL/EXT09-15744, August, 2009.

${ }^{62}$ International Atomic Energy Agency: IAEA Safeguards Glossary - 2001 Edition, International Nuclear Verification Series No. 3, Vienna, Austria, 2002, pp-26 - 27.

${ }^{63}$ International Atomic Energy Agency: Board of Governors Report, GOV/2007/22., Statement by Ambassador Gregory L. Schulte, U.S. Ambassador to United Nations Organizations in Vienna, on Agenda item 6(e) at the IAEA Board of Governors Meeting June 11, 2007.

${ }^{64}$ Bjornard, T., et al.: "Institutionalizing Safeguards-by-Design: High-Level Framework,” U.S. DOE Idaho National Laboratory Report \# INL/EXT-14777, Idaho Falls, ID, January, 2009.

${ }^{65}$ Moeslinger, M.: "The Next Generation Surveillance System (NGSS)," Presentation at the Meeting of the United States Support Program to the IAEA, Vienna, Austria, May 19, 2009. 
${ }^{66}$ Westinghouse Electric Company: "NGNP and Hydrogen Production Conceptual Design Study: Reactor Building Functional and Technical Requirements and Evaluation of Reactor Embedment," Westinghouse Electric Company Document No. NGNP-NHS100-RXBLDG, Revision 0, prepared for Battelle Energy Alliance, September, 2008.

${ }^{67}$ Westinghouse Electric Company: "Reactor Building Functional and Technical Requirements 90\% Design Review," Appendix-A to Westinghouse Electric Company Document No. NGNP-NHS100RXBLDG, Revision 0, prepared for Battelle Energy Alliance, September 2008.

${ }^{68}$ Slabber, J. (PBMR Ltd.): "Reactor Unit and Main Support Systems," Presentation by PBMR (Pty) Ltd. to the U.S. Nuclear Regulatory Commission Public Meeting, PBMR Safety and Design Familiarization, February 28-March 3, 2006, from http://adamswebsearch2.nrc.gov/idmws/doccontent.dll?library=PU_ADAMS^PBNTAD01\&ID=0606801 65.

${ }^{69}$ Slabber, J. (PBMR Ltd.): "Civil Structures and Equipment Arrangements," Presentation by PBMR (Pty) Ltd. to the U.S. Nuclear Regulatory Commission Public Meeting, PBMR Safety and Design

Familiarization, February 28-March 3, 2006, from http://adamswebsearch2.nrc.gov/idmws/doccontent.dll?library=PU_ADAMS^PBNTAD01\&ID=0606801 70.

${ }^{70}$ Slabber, J. (PBMR Ltd.): "PBMR Nuclear Material Safeguards," Paper No. B14, Proceedings of the Conference on High Temperature Reactors, Beijing, China, September, 22-24, 2004, from http://www.iaea.org/inisnkm/nkm/aws/htgr/fulltext/htr2004_b14.pdf.

${ }^{71}$ Bjornard, T. A., et al: "Implementing the Safeguards-by-Design Process," U.S. DOE Idaho National Laboratory Report \# INL/EXT-09-17085, Idaho Falls, ID, October, 2009.

${ }^{72}$ International Atomic Energy Agency, Department of Safeguards: "Joint Use of Safeguards Equipment between the IAEA and an External Party," SGTS/TIE Policy Paper \#20, Vienna, Austria, April 20, 2006.

${ }^{73}$ Moeslinger, M.: "The Next Generation Surveillance System (NGSS)," Presentation at the Meeting of the United States Support Program to the IAEA, Vienna, Austria, May 19, 2009.

${ }^{74}$ Terry, W. K. (ed.): "Modular Pebble-Bed Reactor Project: Laboratory-Directed Research and Development Program - FY 2001 Annual report," Report \#INEEL/EXT-01-01623, U.S. DOE Idaho National Engineering and Environmental laboratory (INEEL), Idaho Fall, ID, and the Massachusetts Institute of Technology (MIT), Cambridge, MA, December 2001, from http://web.mit.edu/pebblebed/PBRLDRDreport2001.pdf

${ }^{75}$ Ougouag, A.M., Terry, W.K., and Gougar, H.D.: "Examination of the Potential for Diversion or Clandestine Dual Use of a Pebble-Bed Reactor to Produce Plutonium," Paper No. 206, HTR-2002: Proceedings of the Conference on High Temperature Reactors, Petten, The Netherlands, April 22-24, 2002, from http://www.iaea.org/inisnkm/nkm/aws/htgr/fulltext/htr2002_206.pdf.

${ }^{76}$ Kadak, A.C.: "Modular Pebble Bed Reactor High Temperature Gas Reactor," Presentation at the American Nuclear Society, 2002 Winter Meeting, Washington, D.C., November 2002, from http://web.mit.edu/pebble-bed/Presentation/MPBRHTGR.pdf.

${ }^{77}$ Kadak, A.C.: "Chinese Research on Future Nuclear Energy Systems," 14th International Security Conference: Strengthening the Nuclear Nonproliferation Regime Focus on the Civilian Nuclear Fuel Cycle, April 6, 2005, from http://www.intlsecconf.sandia.gov/kadak_05isc.pdf. 
${ }^{78}$ Forsberg, C.W. and Moses, D.L.: "Safeguards Challenges for Pebble-Bed Reactors (PBRs): Peoples Republic of China (PRC)," U.S. DOE Oak Ridge National Laboratory Report \#ORNL/TM-2008/229, Oak Ridge, TN, Draft ca. August, 2009.

${ }^{79}$ Ougouag, A. M., Gougar, H.D., and Todd, T. A.: "Evaluation of the Strategic Value of Fully Burnt PBMR Spent Fuel," U.S. DOE Idaho National Laboratory (INL) Report \# INL-EXT-06-11272, Idaho Falls, ID, May, 2006.

${ }^{80}$ Ougouag, A. M., Gougar, H.D., and Todd, T. A. (INL): "Evaluation of the Strategic Value of Fully Burnt PBMR Spent Fuel,” U.S. DOE Idaho National Laboratory (INL) Report \# INL-EXT-06-11272, Idaho Falls, ID, May, 2006.

${ }^{81}$ Hertzler, T. (SAIC): “Technical and Regulatory Review of the Rover Nuclear Fuel Process for Use on Fort St. Vrain Fuel," Prepared by Science Applications International Corporation for EG\&G Idaho and the U.S. Department of Energy, Report \# EGG-WTD-10550, February, 1993.

${ }^{82}$ Stacy, S. and Braun, J.: "Historic American Engineering Record - Idaho National Laboratory, Idaho Chemical Processing Plant Fuel Reprocessing Complex," U.S. DOE Idaho National Laboratory, Report \# INL-EXT-06-11969, Idaho Falls, ID, December, 2006.

${ }^{83}$ Benedict, M., Pigford, T. H., and Levi, H. W.: "Nuclear Chemical Engineering," McGraw Hill Chemical Engineering Series, Second Edition, New York, 1981, pp. 514-526.

${ }^{84}$ Slabber, J.: "Pebble Fuel Advantages," Proceedings of the $2^{\text {nd }}$ International Topical Meeting on High Temperature Reactor Technology,” Beijing, China, September 22-24, 2004.

${ }^{85}$ Bathke, C. G., et al.: "The Attractiveness of Materials in Advanced Nuclear Fuel Cycles for Various Proliferation and Theft Scenarios," Proceedings of Global 2009, U.S. DOE Los Alamos National Laboratory Report \# LA-UR-09-02466, Paris, France, September, 2009.

${ }^{86}$ Bathke, C. G., et al.: "An Assessment of the Attractiveness of Material Associated with a MOX Fuel Cycle from a Safeguards Perspective," U.S. DOE Los Alamos National Laboratory, Los Alamos, NM, ca. October, 2009.

${ }^{87}$ Bowden, N.S., Lawrence Livermore National Laboratory: "Reactor Monitoring and Safeguards Using Anti-neutrino Detectors," Proceedings from the XXIII Conference on Neutrino Physics and Astrophysics, also Journal of Physics: Conference Series-136, \#022008, 2008.

${ }^{88}$ Shropshire, D.E, and Herring, J.S.: "Fuel-Cycle and Nuclear Material Disposition Issues Associated with High-Temperature Gas Reactors," Proceedings of the ANES Meeting, Miami Beach, FL, October 36, 2004.

${ }^{89}$ Moran, B. (International Atomic Energy Agency): Presentation at the Meeting of the United States Support Program to the IAEA, "Geologic Repositories - Safeguards Approach and Technical Requirements," Vienna, Austria, May 18, 2009. 